\title{
Anxiety Evokes Hypofrontality and Disrupts Rule-Relevant Encoding by Dorsomedial Prefrontal Cortex Neurons
}

\author{
Junchol Park, Jesse Wood, Corina Bondi, Alberto Del Arco, and Bita Moghaddam \\ Departments of Neuroscience and Psychiatry, Center for Neuroscience, University of Pittsburgh, Pittsburgh, Pennsylvania 15260
}

\begin{abstract}
Anxiety is a debilitating symptom of most psychiatric disorders, including major depression, post-traumatic stress disorder, schizophrenia, and addiction. A detrimental aspect of anxiety is disruption of prefrontal cortex (PFC)-mediated executive functions, such as flexible decision making. Here we sought to understand how anxiety modulates PFC neuronal encoding of flexible shifting between behavioral strategies. We used a clinically substantiated anxiogenic treatment to induce sustained anxiety in rats and recorded from dorsomedial PFC (dmPFC) and orbitofrontal cortex (OFC) neurons while they were freely moving in a home cage and while they performed a PFC-dependent task that required flexible switches between rules in two distinct perceptual dimensions. Anxiety elicited a sustained background "hypofrontality" in dmPFC and OFC by reducing the firing rate of spontaneously active neuronal subpopulations. During task performance, the impact of anxiety was subtle, but, consistent with human data, behavior was selectively impaired when previously correct conditions were presented as conflicting choices. This impairment was associated with reduced recruitment of dmPFC neurons that selectively represented task rules at the time of action. OFC rule representation was not affected by anxiety. These data indicate that a neural substrate of the decision-making deficits in anxiety is diminished dmPFC neuronal encoding of task rules during conflict-related actions. Given the translational relevance of the model used here, the data provide a neuronal encoding mechanism for how anxiety biases decision making when the choice involves overcoming a conflict. They also demonstrate that PFC encoding of actions, as opposed to cues or outcome, is especially vulnerable to anxiety.
\end{abstract}

Key words: addiction; decision making; dopamine; schizophrenia; stress

Significance Statement

A debilitating aspect of anxiety is its impact on decision making and flexible control of behavior. These cognitive constructs depend on proper functioning of the prefrontal cortex (PFC). Understanding how anxiety affects PFC encoding of cognitive events is of great clinical and evolutionary significance. Using a clinically valid experimental model, we find that, under anxiety, decision making may be skewed by salient and conflicting environmental stimuli at the expense of flexible top-down guided choices. We also find that anxiety suppresses spontaneous activity of PFC neurons, and weakens encoding of task rules by dorsomedial PFC neurons. These data provide a neuronal encoding scheme for how anxiety disengages PFC during decision making.

\section{Introduction}

Anxiety can be an adaptive reaction to stressful or unpredictable life events, but it produces adverse cognitive effects that impede

\footnotetext{
Received Nov. 25, 2015; revised Jan. 29, 2016; accepted Feb. 2, 2016.

Author contributions: J.P. and B.M. designed research; J.P., C.B., A.D., and B.M. performed research; J.P., J.W., and C.B. analyzed data; J.P., J.W., C.B., A.D., and B.M. wrote the paper.

This work was supported by National Institute of Mental Health MH084906 and MH048404 to B.M., and the Pittsburgh Life Sciences Greenhouse to B.M. We thank Drs. Huiyuan Zheng and Linda Rinaman for providing resources and technical support for the elevated plus maze experiment; and members of the B.M. laboratory for useful discussions on the present work.

The authors declare no competing financial interests.

Correspondence should be addressed to Dr. Bita Moghaddam, Center for Neuroscience, University of Pittsburgh, 4200 Fifth Avenue, Pittsburgh, PA 15260. E-mail: bita@pitt.edu.

C. Bondi's current address: Department of Physical Medicine and Rehabilitation, University of Pittsburgh, PA 15260

A. Del Arco's current address: Health, Exercise Science and Recreation Management, School of Applied Science, University of Mississippi, 0xford, MS 38677.
}

ongoing behavior and contribute to clinical manifestation of anxiety disorders (Bishop, 2007; Eysenck et al., 2007). Anxiety also is one of the more debilitating symptoms of psychiatric disorders, including post-traumatic stress disorder, obsessive-compulsive disorder, mood disorders, schizophrenia, and autism (Owens et al., 2005; Solomon et al., 2008; Lüthi and Lüscher, 2014; Ruglass et al., 2014; Hamilton et al., 2015). In addictive disorders, for example, comorbidity with anxiety, as well as the anxiety associated with drug withdrawal during abstinence, are major contributing factors to relapse (Lüthi and Lüscher, 2014; Ruglass et al., 2014).

Human behavioral and imaging investigations have described a complex impact of anxiety on prefrontal cortex (PFC)-related 
cognitive functions, including deficits in flexible control of behavior (Shin et al., 2001; Bishop, 2007; Eysenck et al., 2007). Multiple models have been proposed for proper coping or pathological response to anxiety (Ouimet et al., 2009; Robinson et al., 2013; Adhikari, 2014) and stress (Hains and Arnsten, 2008; Arnsten, 2009). However, the impact of anxiety on spontaneous and phasic activity of PFC neuronal ensembles during cognitivebehavioral performance is largely unknown.

Animal electrophysiological studies of PFC neurons during anxiety have focused primarily on fearful or avoidance behaviors (Sotres-Bayon et al., 2004; Burgos-Robles et al., 2009; Adhikari et al., 2010, 2011). Although these studies have informed us about the representation of fear-related events, such as freezing behavior, anxiety is not limited to a rapid neuronal or behavioral event but often is an enduring state that is sustained for many minutes to hours. More importantly, the negative impact of anxiety extends beyond an aversive feeling and influences ongoing goaldirected behaviors that use cognitive and affective processing at the service of cognitive flexibility.

We sought to determine the impact of a sustained anxiety state on PFC neural processing of a behavior that involved cognitive flexibility. The anxiety state was induced by a pharmacological model with excellent clinical validity. Specifically, extensive literature indicates that inverse agonists of allosteric benzodiazepine binding sites in $\mathrm{GABA}_{\mathrm{A}}$ receptors, such as FG7142, produce anxiety-like physiological, neurochemical, and behavioral effects in rodents (Evans and Lowry, 2007), primates (Ninan et al., 1982; Murphy et al., 1996a, b), and humans (Dorow, 1987). We combined this experimental model of anxiety with unit recording in two subregions of the PFC with particular importance for cognitive control and emotional regulation: the dorsomedial PFC (dmPFC) and orbitofrontal cortex (OFC) (Stefani and Moghaddam, 2005; Darrah et al., 2008; Floresco et al., 2008; Schoenbaum et al., 2009; Durstewitz et al., 2010; Lee, 2013; Likhtik et al., 2014). We assessed the impact of FG7142 on spontaneous activity of $\mathrm{dmPFC}$ and OFC neurons while rats freely moved in their home cage during wake cycle and while they engaged in a rewarded extradimensional set-shifting task. The task, similar to other rodent set-shifting tasks, required rats to guide their instrumental behavior based on two rules involving distinct perceptual dimensions, and switch between the rules. This particular task has been well characterized (Darrah et al., 2008; Floresco et al., 2008) and was selected for its feasibility for multiple extradimensional shifts within each session with electrophysiological recordings.

We found that the anxiogenic treatment induced sustained suppression of the spontaneous activity of subpopulations of $\mathrm{dmPFC}$ and OFC neurons. During task performance, this treatment produced modality-specific behavioral impairment that correlated with reduced recruitment of dmPFC, but not OFC, neurons that encode conflict-related actions.

\section{Materials and Methods}

Subjects and surgical procedure

Male Sprague Dawley rats ( $\sim 400 \mathrm{~g}$, Harlan) were singly housed on a $12 \mathrm{~h}$ light/dark cycle (lights on at 7:00 P.M.). All data were collected during the dark cycle. Animals were not previously exposed to any drugs or behavioral training. Microelectrode arrays were implanted in the $\mathrm{dmPFC}$ and contralateral OFC or bilateral dmPFC (home cage; $n=11$, set-shifting task; $n=8$ rats) of isoflurane-anesthetized rats, and secured with dental cement for chronic recording. The following coordinates (Paxinos and Watson, 1998) were used (relative to bregma): $\operatorname{dmPFC}($ home cage) $=$ $3.0 \mathrm{~mm}$ anterior, $0.7 \mathrm{~mm}$ lateral, $2.2 \mathrm{~mm}$ ventral from skull; dmPFC (set-shifting task) $=3.0 \mathrm{~mm}$ anterior, $0.7 \mathrm{~mm}$ lateral, $4 \mathrm{~mm}$ ventral; and
OFC (home cage and set-shifting task) $=3.0 \mathrm{~mm}$ anterior, $3.3 \mathrm{~mm}$ lateral, $4.5 \mathrm{~mm}$ ventral. Recording sessions began after 1 week of postoperative recovery. At the completion of all recordings, rats were anesthetized with $400 \mathrm{mg} / \mathrm{kg}$ intraperitoneal chloral hydrate and perfused with saline and 10\% buffered formalin. Coronal slices of PFC were collected from each brain and cresyl-violet stained. Placements of electrode arrays were confirmed via light microscope. All procedures were in accordance with the National Institutes of Health's Guide for the Care and Use of Laboratory Animals and were approved by the University of Pittsburgh Institutional Animal Care and Use Committee.

\section{Home-cage recording}

In a home cage recording experiment, single-unit activity was recorded from a freely moving rat in a clear polycarbonate home cage with bedding. After $30 \mathrm{~min}$ of baseline recording, each rat received an intraperitoneal injection of FG7142 (5 or $10 \mathrm{mg} / \mathrm{kg}$ in vehicle) or $1.0 \mathrm{ml} / \mathrm{kg}$ vehicle (one drop Tween 80 in $10 \mathrm{ml}$ distilled water). Neuronal activity was recorded for $120 \mathrm{~min}$ after injection. The order of injections was randomized across rats with at least $3 \mathrm{~d}$ of washout period between injections.

\section{Set-shifting task}

In a set-shifting experiment, a rat received an intraperitoneal injection of vehicle, 5 or $10 \mathrm{mg} / \mathrm{kg} \mathrm{FG7142.} \mathrm{Ten} \mathrm{minutes} \mathrm{were} \mathrm{allowed} \mathrm{after} \mathrm{the} \mathrm{in-}$ jection before placing the rat in the operant chamber. After a $3 \mathrm{~min}$ habituation period in the chamber, the task was initiated. The order of injection was randomized for each rat with at least $3 \mathrm{~d}$ of washout period before the next injection.

\section{Training and testing of the set-shifting task}

Rats were placed on a restricted diet of $13 \mathrm{~g}$ of food/rat/d with free access to water to maintain $\sim 85 \%$ of their free-feeding weight. Rats were trained on an extradimensional set-shifting task that requires instrumental action according to two discrimination rules, each involving a distinct perceptual dimension, spatial position, and a light cue (see Fig. 2a). For training parameters and detailed characterization of this task, see Darrah et al. (2008). Both perceptual dimensions in this task involve a light cue presented at one of the two cue ports. Performance according to the "Light" discrimination rule (light rule) requires a nose poke to the illuminated cue port, regardless of its spatial location for a reward pellet (see Fig. 2a). Performance according to the "Side" discrimination rule (side rule) requires a nose poke to the cue port at a designated spatial location (valid side; left or right), regardless of illumination (see Fig. $2 a$ ). In side rule trials, the light cue was presented in the pseudo-randomly selected side to ensure that the cue was presented at each side no more than two consecutive trials. Rats were trained on an initial rule (dimension) to a performance criterion of 10 consecutive correct (rewarded) responses, and then immediately switched to the alternate rule.

After pretraining, rats were trained daily on the set-shifting task, being required to shift their response patterns between the light and side rules. Each session consisted of four sets. The first set was pseudo-randomly assigned with either light or side rule. After 10 consecutive correct responses, the next set with the alternate rule commenced. Set-shifting was not explicitly signaled; thus, rats had to learn it by trial and error based on delivery or omission of the reward. A successful training session consisted of 4 sets completed in $90 \mathrm{~min}$. For the counterbalancing of the poke direction, the light cue was not presented in the same port more than twice. In addition, each session included two side rule sets using right and left ports as the valid side; thus, the side rule trials included equivalently mixed right- and left-poking trials. After establishing stable baseline performance (at least 3 consecutive successful sessions), rats were subjected to electrode implantation surgery. The first recording was initiated only after the recovery of the stable baseline performance.

In each trial, a correct response was rewarded with a sugar pellet, whereas an incorrect response was not rewarded. Occurrence of an incorrect response reset the number of consecutive trials to 0 . Immediately after each response, the food trough in the opposite wall of the chamber was illuminated, regardless of the accuracy of response, until rats poked to the trough to end the trial. After $10 \mathrm{~s}$ intertrial interval, the next trial was initiated as the light cue was turned on. 


\section{Electrophysiology}

Single-unit activity was recorded simultaneously via bilateral eightchannel Teflon-insulated stainless steel $50 \mu \mathrm{m}$ microwire arrays (NB Laboratories). Unity-gain junction field effect transistor headstages were attached to a headstage cable and commutator nonrestrictive to the animals' movement. Signals were amplified via a multichannel amplifier (Plexon). Spikes were bandpass filtered between $220 \mathrm{~Hz}$ and $6 \mathrm{kHz}$, amplified $500 \times$, and digitized at $40 \mathrm{kHz}$. Single-unit activity was then digitally high-pass filtered at $300 \mathrm{~Hz}$ and LFP were low-pass filtered at 125 $\mathrm{Hz}$. Threshold crossing spike waveforms were stored for offline analysis. Single units were sorted using the Offline Sorter software package (Plexon). Single-unit activity was further analyzed only if the unit displayed a stable waveform throughout the recording session. To prevent analysis of the same unit recorded on different channels, we examined cross-correlograms. If a unit presented a peak of activity at the time of the reference unit's firing, only one of the two was further analyzed. Because each animal was allowed at least $3 \mathrm{~d}$ of washout between recording sessions, we treated units recorded in different sessions as different units despite the fact that the same unit may have been serially recorded. This approach allowed for the most conservative assessment of unit identity. Units meeting these criteria were used in all single-unit analyses. We did not exclude putative fast-spiking interneurons from our samples. Only $1.9 \%$ of total units displayed the mean firing rates $>20 \mathrm{~Hz}$.

Neural data analysis for the home cage recording

Analyses of single-unit data were conducted with MATLAB (The MathWorks) and SPSS statistical software (IBM). The drug-free baseline period was 27 min consisting of $9 \times 3$ min bins, and the postinjection period was $108 \mathrm{~min}$ of $36 \times 3 \mathrm{~min}$ bins. Each unit's activity in the baseline and postinjection periods was $Z$-score normalized using the mean and the SD of the baseline firing rate. Differences in baseline firing rate between dose groups were assessed with the Kruskal-Wallis test. Two-way repeated-measures ANOVA was used to assess the effects of dose, time period, and their interaction on the population activity. Post hoc analyses with Bonferroni correction were used for between- and within-dose group comparisons subsequently. For all tests, the Greenhouse-Geisser correction was applied as necessary. All statistical tests were specified as two-sided.

To examine how the FG7142-induced inhibitory effect on population activity was manifested in individual units, each unit was classified based on modulation of its postinjection activity. For classification, the upper and lower bounds of the $95 \%$ confidence interval of the normalized activity were used (Homayoun and Moghaddam, 2007). Units crossing the upper or lower bound in 3 consecutive 3 min bins were classified into the "Activated" or "Inhibited" subgroup, respectively. Units that satisfied both criteria in different time bins were grouped as "Bidirectional." The remaining units were labeled as "No-change." The distribution of units in these subgroups was compared between dose groups using the fisher's exact test. All $\alpha$ levels were set to 0.05 .

\section{Behavioral data analysis for the set-shifting task experiment}

All behavioral performance measures (the numbers of trials to criterion, errors, percentage of correct trials, and reaction time) were quantitated, including all corresponding trials. For all eight rats, a binomial test (onetailed) was used to examine whether each rat performed the task significantly above the chance level. One-way ANOVA was used to assess the dose effect on total trials and time to complete the task. Two-way repeated-measures ANOVA was used to examine the effect of dose, rule, and their interaction on the number of trials to criterion, the number of errors, the percentage of correct trials, and the reaction time for action or food trough entry. Post hoc tests used the Bonferroni procedure.

\section{Neural data analysis for the set-shifting task experiment}

Baseline and periaction activity analysis. To examine how FG7142 affected the baseline neuronal activity during task performance, the firing rate of each unit was measured within the $3 \mathrm{~s}$ window beginning $3.5 \mathrm{~s}$ before each trial onset, averaged across trials, and compared across dose groups. To assess the individual neuronal activity within periaction time periods, each unit's firing rate was computed in $50 \mathrm{~ms}$ bins within the periaction windows $(-2$ to $2 \mathrm{~s}$ relative to the action occurring at time $=0)$. The firing rate of each unit was averaged across trials. The trial-averaged firing rate of each unit was $Z$-score normalized to that of its baseline period. Units were categorized as "Activated" or "Inhibited" within preaction ( -2 to $0 \mathrm{~s}$ ) and postaction ( 0 to $2 \mathrm{~s}$ ) relative to the action occurring at time $=0$ periods, if their average normalized activity contained two or more consecutive $50 \mathrm{~ms}$ bins with $Z>1.96$ or $Z<-1.96$, respectively. The remaining units were categorized as "No-change." These criteria were validated using a bootstrap analysis on the baseline period (a $2 \mathrm{~s}$ window beginning $2.5 \mathrm{~s}$ before the trial onset) of each unit. For each unit, the baseline window was randomly sampled with replacement 10,000 times. The proportion of $2 \mathrm{~s}$ windows that resampled activity reached the significance criteria is a measure of the expected false-positive rate for that unit during any $2 \mathrm{~s}$ window. The expected false-positive rate was $\alpha=$ 0.0023 . Differences in the distribution of neuronal responses (activated, inhibited, or no-change) between dose groups were assessed with Fisher's exact test. The normalized population activity in the preaction or postaction period was compared across dose groups, using one-way ANOVA.

Linear regression analysis. A multiple linear regression model was used to investigate how each unit encoded task-relevant information. The following multiple linear regression model was used:

$$
\begin{array}{r}
\text { Spike Count }=\beta_{0}+\beta_{1} \mathrm{TR}(\mathrm{t})+\beta_{2} \mathrm{R}(\mathrm{t})+\beta_{3} \mathrm{R}(\mathrm{t}-1)+\beta_{4} \mathrm{D}(\mathrm{t}) \\
+\beta_{5} \mathrm{D}(\mathrm{t}-1)+\beta_{6} \mathrm{RT}(\mathrm{t})
\end{array}
$$

where TR(t) represented the task rule on trial $t$ ( 0 if light, 1 if side), $R(t)$ is the response outcome on trial $\mathrm{t}$ ( 1 if correct, 0 if incorrect), $\mathrm{R}(\mathrm{t}-1)$ is the previous response outcome on trial $t-1$ ( 1 if correct, 0 if incorrect), $\mathrm{D}(\mathrm{t})$ is the poke direction on trial $\mathrm{t}(1$ if right, 0 if left), $\mathrm{D}(\mathrm{t}-1)$ is the poke direction on trial $t-1$ ( 1 if right, 0 if left), $R T(t)$ is the reaction time on trial $\mathrm{t}$ ( 1 if high, 0 if medium, -1 if low latency, for each animal). To investigate the neural representation of the task rule specifically in CF trials, we used a slightly modified regression model (below) in which we selected CF trials in both side and light rule sets, and then examined the encoding of CF trials of one rule, relative to the trials of the other rule.

Spike Count $=\beta_{0}+\beta_{1} \mathrm{TR}(\mathrm{t} ; \mathrm{CF})+\beta_{2} \mathrm{R}(\mathrm{t})+\beta_{3} \mathrm{R}(\mathrm{t}-1)+\beta_{4} \mathrm{D}(\mathrm{t})$

$$
+\beta_{5} \mathrm{D}(\mathrm{t}-1)+\beta_{6} \mathrm{RT}(\mathrm{t})
$$

where TR(t; CF) represented CF trials of one rule (1) and all trials of the other rule (0), and all the other terms were represented identically as in the above regression model. Initial trials of each set were excluded from the regression analysis to ensure that rats were aware of the set-shifting. Both correct and incorrect trials after the fifth correct response of each set were included. The regression analysis was conducted for the spike count of each unit, in a window of $1 \mathrm{~s}$ width that slides in steps of $0.2 \mathrm{~s}$ within the range of $2 \mathrm{~s}$ before and after the instrumental action. Units that had (1) three or more consecutive or (2) four or more sliding windows with significant coefficients $(p<0.05$, based on the $t$ test) for each covariate $\left(\beta_{1}\right.$ to $\left.\beta_{6}\right)$ during the periaction time period of interest were considered to encode the corresponding variable. The stringency of this criterion was verified by calculating the false-positive rate when the regression was performed on bootstrap resampled trials (1000 samples; the expected false-positive rate $<0.05$ ). To compare the proportions of units signaling trial types, current or previous response outcome between dose groups, Fisher's exact test was used.

To investigate how the dmPFC neural representation of the task rule evolved from early to late phases of a set, trials in each session were divided into two subsets: one comprising the first half of the trials in each set and the other comprising the second half of the trials. We then quantified the neuronal selectivity for the two rules using a sliding receiver operating characteristic (ROC) analysis (see Fig. 8c). The area under the ROC curve was used as an index of neuronal selectivity. A value of 0.5 was indicative of no selectivity between two conditions, whereas a value of 1 was interpreted as complete discriminability. ROC values were calculated with a sliding $0.4 \mathrm{~s}$ window in $0.2 \mathrm{~s}$ steps. The peak ROC values in the preaction period were used for comparison. A ROC analysis also was applied to the rule-encoding dmPFC units to quantify their discriminability of the rule in side CF and light CF trials (see Fig. 10c). 
Population decoding analysis. After examining the individual neuronal encoding of task variables, we quantified the population level coding using a Poisson naive Bayes' classifier. In general, this decoding method works by training the classifier to "learn" which patterns of neural activity are indicative of particular task conditions (e.g., which is the current rule). In the training phase, the association of different patterns of neural activity with different task conditions is learned from a subset of data (training set). In the test phase, the reliability of the association is then assessed with a separate set of data (test set) based on how accurately the classifier can predict the present task conditions.

For training and testing, we used a cross-validation procedure with the following steps. (1) For each neuron, data from 20 trials were randomly selected for each of the 2 conditions (e.g., light and side rules). For each of these trials, data from all neurons were concatenated to create a pseudopopulation response vector (i.e., neurons that were recorded under the same conditions but in separate sessions were treated as if they had been recorded simultaneously). (2) These pseudo-population vectors are grouped into 20 splits of the sampled data, with each split containing one pseudo-population response vector for each task condition. (3) A classifier was trained using 19 splits of the data and tested with the remaining split. This procedure was repeated 20 times, leaving a different split at each time (i.e., a 20 -fold leave-one-split-out cross-validation was used) (Meyers et al., 2012). This procedure (steps 1-3) was repeated 50 times for each $200 \mathrm{~ms}$ window sliding in steps of $50 \mathrm{~ms}$ within the $4 \mathrm{~s}$ periaction period.

Specifically in each repetition, we have a Poisson likelihood function given by the following:

$$
P\left(\underline{x}_{t} \mid C_{k}\right)=\prod_{i=1}^{D} \frac{\lambda_{k i, t}^{x_{i, t}} e^{-\lambda_{k i, t}}}{x_{i, t} !}
$$

where $\underline{x}_{t}$ is a pseudo-population vector of spike counts at $t^{\text {th }}$ sliding

window within a trial, $k$ indicates a particular rule (side or light) or a response outcome (correct or incorrect response); thus, $k$ takes on either 1 or $2 . i$ indicates unit label, 1 to $D . \lambda_{k i, t}$ is the parameter for the Poisson distribution estimated by the following:

$$
\lambda_{k i, t}=\frac{1}{N_{k}} \sum_{n \in C_{k}} x_{n i, t}
$$

The posterior probability of a particular rule or an outcome given the spike count vector is provided by Bayes' theorem as follows:

$$
P\left(C_{k} \mid \underline{x}_{t}\right)=\frac{P\left(\underline{x}_{t} \mid C_{k}\right) P\left(C_{k}\right)}{P\left(\underline{x}_{t}\right)}
$$

We assumed a flat prior probability; thus, $P\left(C_{k}\right)$ is a constant. Hence, the classifier predicts the task condition with maximum probability given the pseudo-population activity.

$$
\widehat{C_{k}}=\operatorname{argmax}_{k} P\left(\underline{x}_{t} \mid C_{k}\right)
$$

The result of population decoding analysis was quantified as the percentage of correctly predicted test splits, which we termed "decoding accuracy." The mean and SD of decoding accuracy were calculated across the scores of 50 resampling procedures.

To examine whether there are dynamic temporal patterns in the dmPFC neuronal signaling of the task rule (i.e., do the neurons encode the task rule differentially at different times), we ran a temporal-crosstraining analysis (Meyers et al., 2012) (see Fig. $9 c-e$ ). In this analysis, a classifier is trained with data from one time point and then tested on data from different trials that were taken either from the same time period or a different time period, using the same steps (1-4) described above.

\section{Behavioral testing on the elevated plus maze}

Although numerous previous reports have established the anxiogenic effects of FG7142 (Pellow and File, 1986; Cole et al., 1995; Atack et al., 2005), we assessed the effect of FG7142 versus vehicle on the elevated plus maze (EPM) to ensure that a similar effect is replicated in our hands. Ten minutes after injection, rats were transported into the testing room and placed on the center of the EPM with their heads facing an open arm. The experimenter then left the room, and the rat's behavior was video recorded for $5 \mathrm{~min}$. The EPM consisted of two open arms $(45 \times 10 \mathrm{~cm})$ with transparent 1-cm-high edging, and two closed arms $(45 \times 10 \times 48$ $\mathrm{cm})$ diverging from a common central platform $(10 \times 10 \mathrm{~cm})$ elevated 90 $\mathrm{cm}$ above the floor. Video records were analyzed using an automatic video tracking software (ANY-maze, Stoelting) to quantify the following: (1) time spent in the open arms, closed arms, or center platform; (2) number of entries made into open and closed arms; and (3) total distance traveled on the maze. These measures were compared between vehicle and FG7142-injected groups using independent-samples $t$ test.

\section{Results}

\section{Inhibitory effect of FG7142 on PFC neuronal population activity}

In total, $138 \mathrm{dmPFC}$ and 184 OFC units were recorded from histologically verified electrodes of 11 freely behaving rats in home cages (Fig. 1a); the mean baseline firing rate before administration of drug was $5.67 \pm 0.50 \mathrm{~Hz}$ in $\mathrm{dmPFC}$ and $4.47 \pm 0.35$ $\mathrm{Hz}$ in OFC. There was no difference in these levels across dose groups in either subregion (Kruskal-Wallis test, dmPFC; $\chi_{2}^{2}=$ $3.32, p=0.19$, OFC; $\left.\chi_{2}^{2}=2.03, p=0.36\right)$.

We examined the impact of doses of FG7142 ( 5 and $10 \mathrm{mg} / \mathrm{kg}$ ) that produces physiological, neurochemical, and cognitive deficits (Murphy et al., 1996b; Mikkelsen et al., 2005; Evans and Lowry, 2007; Pehrson et al., 2013) without inhibiting the animals' motor abilities. Treatment with FG7142 (10 mg/kg i.p.) reduced the spontaneous firing rate of subpopulations of $\mathrm{dmPFC}$ and OFC units (Fig. 1b-e). We quantified the impact of FG7142 on both population activity $(Z$-score) and on individual units. For the latter, units that fired significantly below or above preinjection baseline in 3 consecutive 3 min bins were classified as "Inhibited" and "Activated." Units that were both inhibited and activated were classified as "Bidirectional." The remaining units were classified as "No-change." In the dmPFC, a significant interaction between dose group and time period was observed (two-way repeated-measures ANOVA, $F_{(2,135)}=8.58, p<$ 0.001 ). Both 5 and $10 \mathrm{mg} / \mathrm{kg}$ doses of FG7142 suppressed population activity compared with baseline or vehicle (Fig. 1f; post hoc test, $p$ values $<0.01$ ). A substantial proportion of units inhibited, whereas fewer units increased or bidirectionally modulated their firing rates. The distribution of units in inhibited, activated, and bidirectional subgroups was significantly different from that of vehicle units (Fig. $1 g ; \chi^{2}$ test, $5 \mathrm{mg} / \mathrm{kg} ; \chi_{3}^{2}=10.61, p=0.014,10$ $\left.\mathrm{mg} / \mathrm{kg} ; \chi_{3}^{2}=17.51, p=0.0006\right)$. OFC population activity was suppressed by FG7142 in a similar manner. A significant interaction between dose group and time period was detected (two-way repeated-measures ANOVA, $\left.F_{(2,179)}=8.39, p=3.0 \times 10^{-4}\right)$. FG7142 at $5 \mathrm{mg} / \mathrm{kg}$ significantly suppressed population activity compared with baseline or vehicle (Fig. $1 h$; post hoc test, $p$ values $<0.0001)$. A significant suppression was observed compared with that of the baseline (post hoc test, $p=0.009$ ), as well as a trend toward suppression compared with that of vehicle injection (post hoc test, $p=0.07$ ) after $10 \mathrm{mg} / \mathrm{kg}$ injection. A substantial proportion of units inhibited their activity, and the distribution of inhibited, activated, and bidirectional subgroups was significantly different from that of vehicle units (Fig. $1 i ; \chi^{2}$ test, $5 \mathrm{mg} /$ $\left.\mathrm{kg} ; \chi_{3}^{2}=17.42, p=0.0006,10 \mathrm{mg} / \mathrm{kg} ; \chi_{3}^{2}=9.56, p=0.023\right)$. In both dmPFC and OFC, we verified that the interactions between dose group and time period were significant, when examined using the raw firing rates without $Z$-score normalization (twoway repeated-measures ANOVA, dmPFC; $F_{(2,135)}=3.16, p<$ 


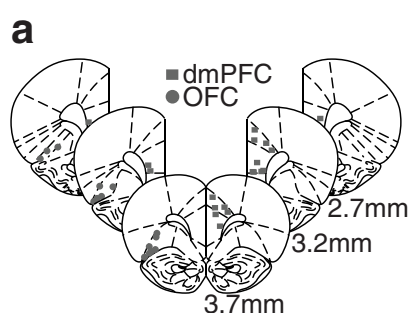

f

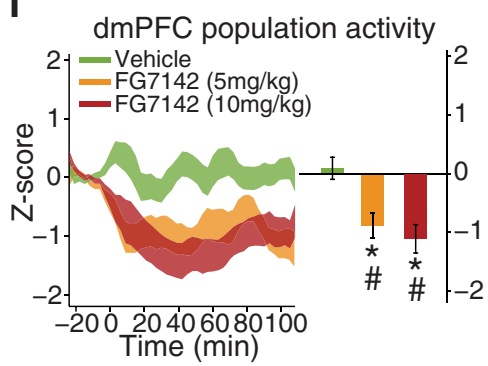

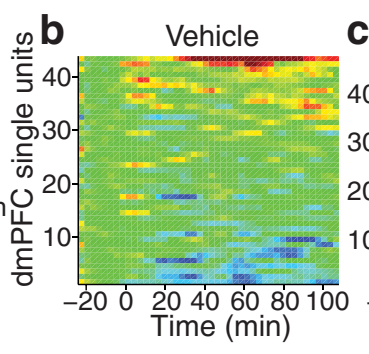

g

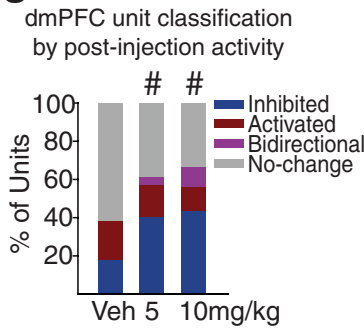

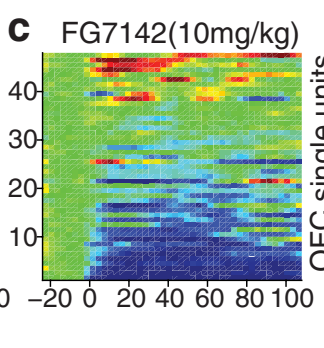

h

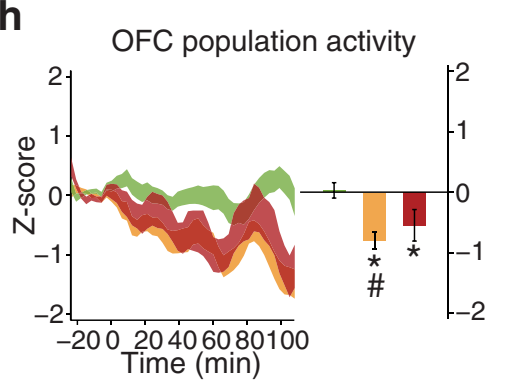

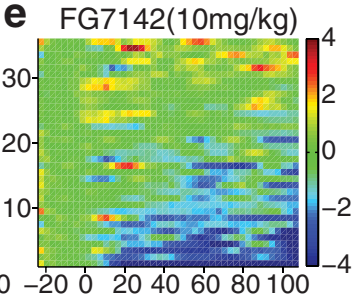

i

OFC unit classification by post-injection activity

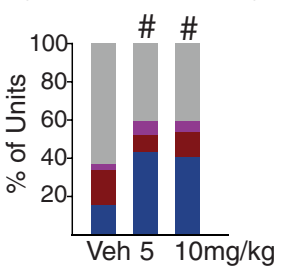

Figure 1. Modulation of PFC single-unit and population activity by FG7142. $\boldsymbol{a}$, Histologically verified placements of dmPFC (squares) and OFC (circles) electrodes used for home cage and set-shifting task recording. $\boldsymbol{b}, \boldsymbol{c}$, The baseline-normalized activity (Z-score) of all dmPFC single units before and after vehicle (b) or $10 \mathrm{mg} / \mathrm{kg}$ FG7142 (c) injection. Baseline activity is normalized to 0 , and injection occurred at time $=0$. Each row represents activity of an individual unit arranged by direction and magnitude of activity change. The number of units $(n)$ and rats $(N)$ : vehicle, $n=$ $44, N=8 ; 5 \mathrm{mg} / \mathrm{kg}, n=47, N=7 ; 10 \mathrm{mg} / \mathrm{kg}, n=47, N=7 . \boldsymbol{d}, \boldsymbol{e}$, The baseline-normalized activity of all 0FC single units: vehicle, $n=76, N=9 ; 5 \mathrm{mg} / \mathrm{kg}, n=71, N=10 ; 10 \mathrm{mg} / \mathrm{kg}, n=37$, $N=8$. $f$, Left, The normalized dmPFC population activity before and after FG7142 or vehicle injection, displayed as mean \pm SE (shaded area). Right, The mean population activity averaged across the entire postinjection period. *Statistically significant difference compared with preinjection baseline. \#Statistically significant difference compared with vehicle. Error bars indicate SE. FG7142 injection led to suppression of the population activity compared with the preinjection baseline or the vehicle control. $\boldsymbol{g}$, Proportion of dmPFC units classified based on the postinjection activity. "Significant difference in the distribution of classified units compared with the vehicle. Increased proportions of FG7142-injected units were classified as inhibited compared with vehicle units. $\boldsymbol{h}$, The normalized OFC population activity and the mean population activity during the postinjection period. $i$, Proportion of OFC units classified based on the postinjection activity.

0.05, OFC; $\left.F_{(2,179)}=10.21, p<1.0 \times 10^{-4}\right)$. Similarly, in both regions, we observed significant suppression of the raw population activity from the baseline after 5 or $10 \mathrm{mg} / \mathrm{kg}$ injection of FG7142 (post hoc test, $p$ values $<0.003$ ).

\section{Impact of FG7142 on set-shifting task performance}

We investigated changes in $\mathrm{dmPFC}$ and $\mathrm{OFC}$ neural correlates that may underlie alterations in cognitive behavior in anxiety. Rats were trained in an operant set-shifting task (Darrah et al., 2008). This task demands a high cognitive load and requires rulebased control of instrumental behavior by requiring rats to discriminate between two rules, each involving a distinct perceptual dimension: spatial location and a light stimulus (Fig. 2a). Thus, the task requires rats to form associations between a stimulus, a response, and an outcome for each rule, and then flexibly switch between the two rules based on the response outcome. Animals were trained before electrode implantation to successfully perform 3 consecutive extradimensional shifts per test session, with sets pseudo-randomized for each session. Stable baseline performance ( 3 consecutive successful sessions) was reached in $18 \pm 3.0$ training sessions. Performance remained consistent after the surgical implantation of electrode arrays (total trials; one-way ANOVA, $F_{(1,14)}=0.44, p=0.52$, total time; one-way ANOVA, $F_{(1,14)}=0.53$, $p=0.48$, number of trials to criterion; two-way repeated-measures ANOVA, $F_{(1,14)}=1.74, p=0.21$, number of errors; two-way repeated-measures ANOVA, $\left.F_{(1,14)}=1.58, p=0.23\right)$.

Systemic injection of FG7142 did not impede the ability of animals to engage in and to complete the set-shifting task. Animals performed well above the chance level (binomial test, $p$ values $<2.32 \times 10^{-7}$ ) and did not display overt performance impairment. The number of total trials required to complete the task (i.e., to perform three consecutive extradimensional shifts) was similar across vehicle and dose groups (Fig. $2 b$; one-way
ANOVA, $\left.F_{(2,21)}=1.28, p=0.30\right)$. Total time taken to complete the task also was not significantly different across groups (Fig. 2b; one-way ANOVA, $\left.F_{(2,21)}=1.91, p=0.17\right)$. This allowed us to move forward with analyzing specific aspects of rule-dependent performance without confounding effects of the anxiogenic treatment producing motor and indiscriminate cognitive impairments. We then compared the number of trials to criterion (10 consecutive correct trials) in the light and side rule sets across dose groups. A significant interaction between dose and rule was found, as rats that received FG7142 reached the criterion with fewer trials in the light rule, but with more trials in the side rule sets compared with when they received vehicle injection (Fig. $2 c$; two-way repeated-measures ANOVA, $F_{(2,21)}=4.26, p=0.028$, post hoc test, $10 \mathrm{mg} / \mathrm{kg}, p=0.012)$. The rule-dependent modulation of performance was echoed in the number of errors. A significant interaction between dose and rule was found with the number of errors in side rule sets increasing, and that of the light rule sets decreasing after FG7142 injection (Fig. 2d; twoway repeated-measures ANOVA, $F_{(2,21)}=5.93, p=0.009$; post hoc test, $10 \mathrm{mg} / \mathrm{kg}, p<0.001)$. Similar numbers of trials to criterion and errors were detected in the side- and light rule sets during performance after vehicle injection (post hoc test, vehicle, $p$ values $>0.21$ )

Performance during the side rule sets was further subtyped based on correspondence between illuminated and correct side (Fig. $2 a$, bottom right). Specifically, in approximately half of the pseudo-randomly selected side rule trials, the correct choice was the illuminated side (nonconflict [NCF] trials), whereas the incorrect choice side was illuminated in the rest of the trials (conflict $[\mathrm{CF}]$ trials). Trials in the light rule set also were subtyped based on correspondence between illuminated and previously correct side (Fig. $2 a$, bottom left). In approximately half of the light rule trials, a light cue was presented in the previously correct 

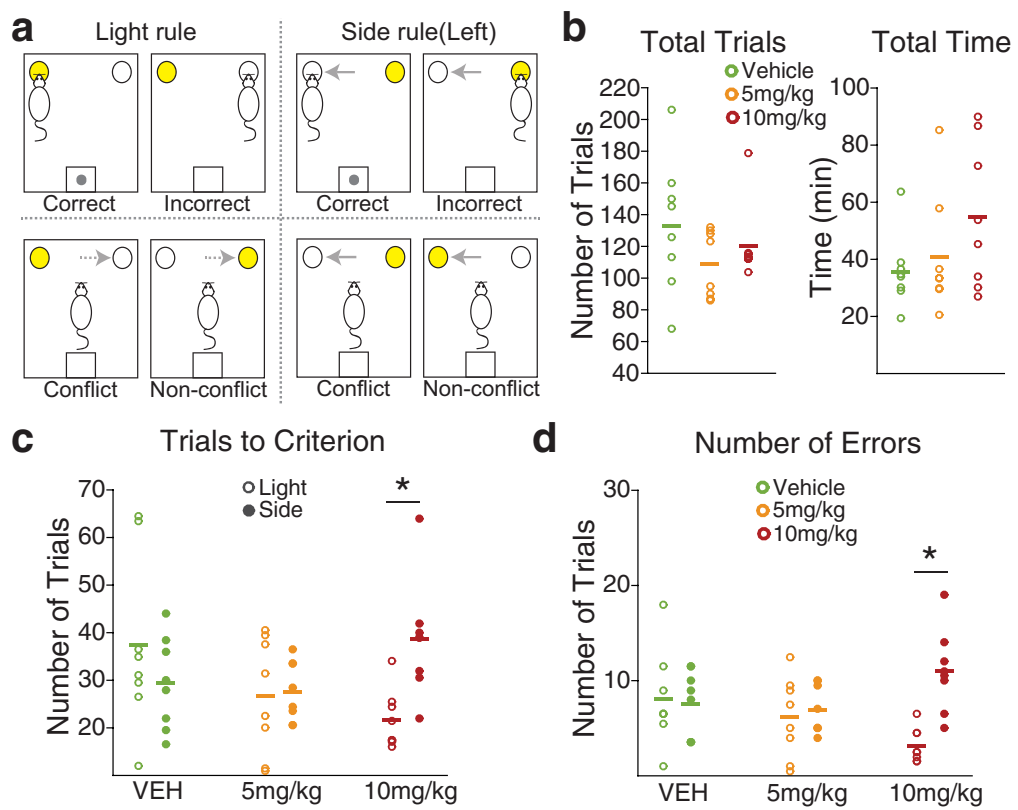

d
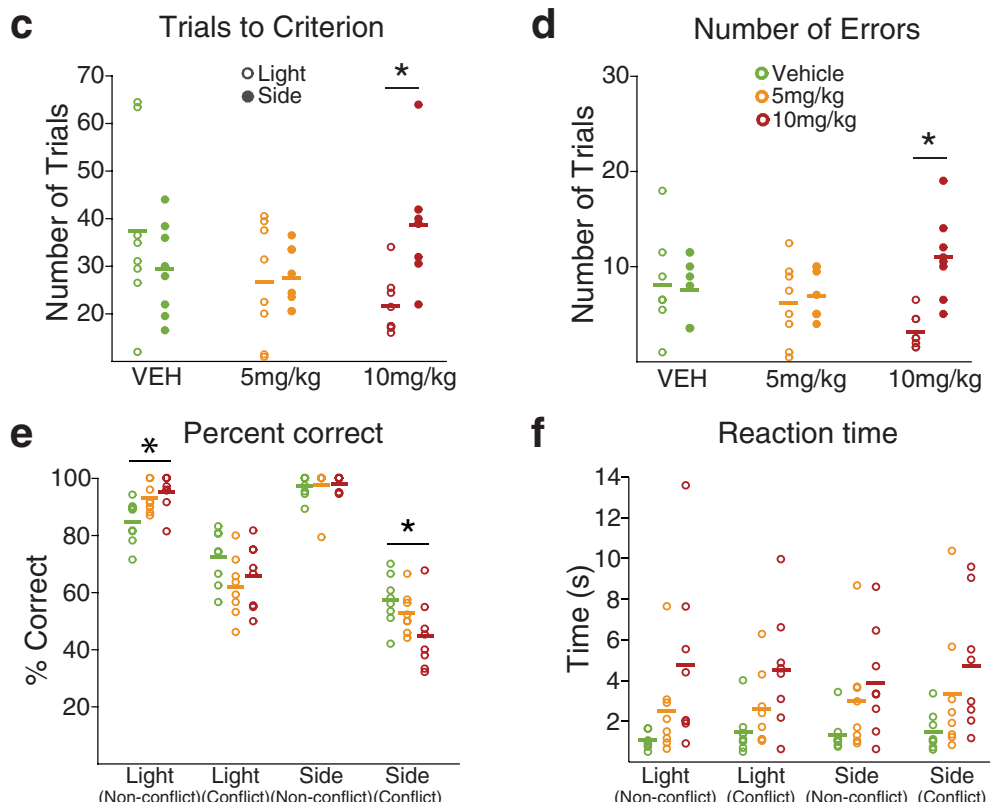

f

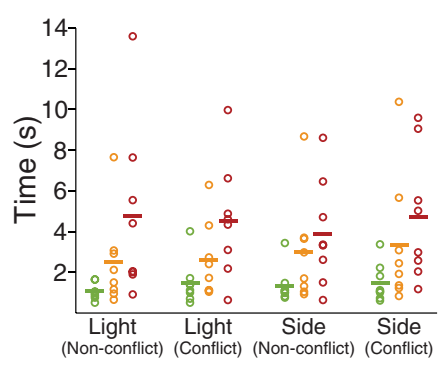

Figure 2. Modulation of set-shifting task performance by FG7142. $\boldsymbol{a}$, Top left, Example correct performance in the light rule, where a nose poke to the illuminated port is rewarded. Bottom left, Light rule trials were subtyped to conflict or nonconflict trials, based on correspondence between illuminated and previously valid side indicated with dotted arrows. Top right, Example correct performance in the side rule, where a nose poke to the valid side (e.g., the left port) is rewarded, regardless of illumination. Bottom right, Side rule trials were subtyped to conflict or nonconflict trials, based on correspondence between illuminated and valid side indicated with solid arrows. $\boldsymbol{b}$, The number of total trials and total time to complete the task were equivalent across dose groups. Each circle represents an individual data point. Horizontal bar represents the mean of each dose group. $\boldsymbol{c}$, The number of trials to reach the set-shifting criterion (10 consecutive correct trials) in light and side rule sets was displayed for each dose group. $\boldsymbol{d}$, The number of errors in light and side rule sets was displayed for each dose group. * Significant difference in the number of trials to the criterion or errors between light and side rule sets. $\boldsymbol{e}$, Distinct choice accuracy was observed in different trial types. All rats were more prone to errors in conflict trials. Such error propensity was more pronounced under the side rule, especially in the $10 \mathrm{mg} / \mathrm{kg}$ treated rats. * Significant difference compared with the vehicle-treated rats. $\boldsymbol{f}$, The RT from the cue onset to the action trended toward a dose-dependent increase in all trial types.

side (NCF trials), whereas the light cue was presented in the previously incorrect side in the other half of the trials (CF trials). A significant effect of trial type was found on the percentage correct, indicating distinct performance depending on trial types (Fig. 2e; two-way repeated-measures ANOVA, $F_{(3,63)}=172.15, p<1.0 \times$ $\left.10^{-4}\right)$. As expected, animals' performance was more prone to errors in CF trials compared with NCF trials, especially during the side rule trials (Fig. $2 e$; post hoc test, $p$ values $<0.032$ ). Treatment with FG7142 significantly modified the error rates in the side CF trials. A significant interaction between dose and trial type was found $\left(F_{(6,63)}=4.05, p=0.002\right)$, and post hoc analysis revealed that the percentage correct in the side rule CF trials was lower during performance after $10 \mathrm{mg} / \mathrm{kg}$ injection, compared with that of vehicle injection (Fig. $2 e$; post hoc test, $p=0.049$ ). Percentage correct in light CF trials was higher than that of side CF trials and did not differ across dose groups (Fig. $2 e$; post hoc test, $p$ values $>0.18$ ). Performance in NCF trials was equivalent (side rule) or even greater (light rule) after FG7142 injection. Collectively, these performance patterns indicate that anxiety induces a response bias toward the light cue, leading to increased distractibility by the irrelevant cue in the side rule, but equivalent or even enhanced performance in light rule trials. Reaction time (RT), the latency from the cue onset to the action (nose poke), also was measured separately for each trial type. In all trial types, RT trended toward a dose-dependent increase but did not significantly differ across dose groups (Fig. 2f; two-way repeated-measures ANOVA, post hoc test, $p$ values $>0.06)$. The latency for reward retrieval was similar across dose groups, indicating that the increase in RT is not associated with indiscriminate changes in locomotion or motivation for reward (two-way repeated-measures ANOVA, post hoc test, $p$ values $>0.9$ ).

\section{Impact of FG7142 on neural correlates of set-shifting task performance}

The PFC neural correlates of task performance in response to FG7142 were analyzed at individual neuronal and population levels, based on single-unit activity recorded from histologically verified electrodes in dmPFC and OFC (Fig. 1a). We first quantified the baseline firing rate and the baseline-normalized periaction activity across all trials. The time of action was identified by the detection of an entry to the nose-poke port, and all preaction or postaction neuronal activity was aligned to timing of the port entry. Consistent with the home cage recording result, dmPFC units in FG7142-treated groups had lower baseline firing rates compared with the vehicle treated units (Fig. 3d; one-way ANOVA, $\left.F_{(2,188)}=5.90, p=0.003\right)$. However, the trial-averaged normalized activity (Fig. $3 e$; one-way ANOVA, $F_{(2,188)}=0.82$, $p=0.44)$ and the fraction of activated units (Fig. $3 f ; \chi^{2}$ test, $p$ values $>0.07$ ) within the preaction or postaction period did not differ across dose groups.

In OFC, a nonsignificant reduction in the baseline firing rate was observed in FG7142-treated units (Fig. 4d; one-way ANOVA, $\left.F_{(2,84)}=0.78, p=0.46\right)$. This contrasted the significant reduction observed during home cage recording and may be due to the impact of context (operant box vs home cage) on the baseline spontaneous activity of OFC neurons, or the difference in the statistical power given the different sample sizes. Unlike dmPFC units, and as expected, OFC units responded more robustly during the postaction (outcome) period (Fig. $4 a-c$ ). This postaction OFC response was not affected by FG7142, as similar trialaveraged normalized activity (Fig. $4 e$; one-way ANOVA, $F_{(2,84)}=$ $0.14, p=0.87$ ) and fraction of activated units (Fig. $4 f ; \chi^{2}$ test, $p$ values $>0.24$ ) were observed across dose groups.

We then examined the individual neuronal encoding of various task-relevant variables, such as the rule, current and previous 

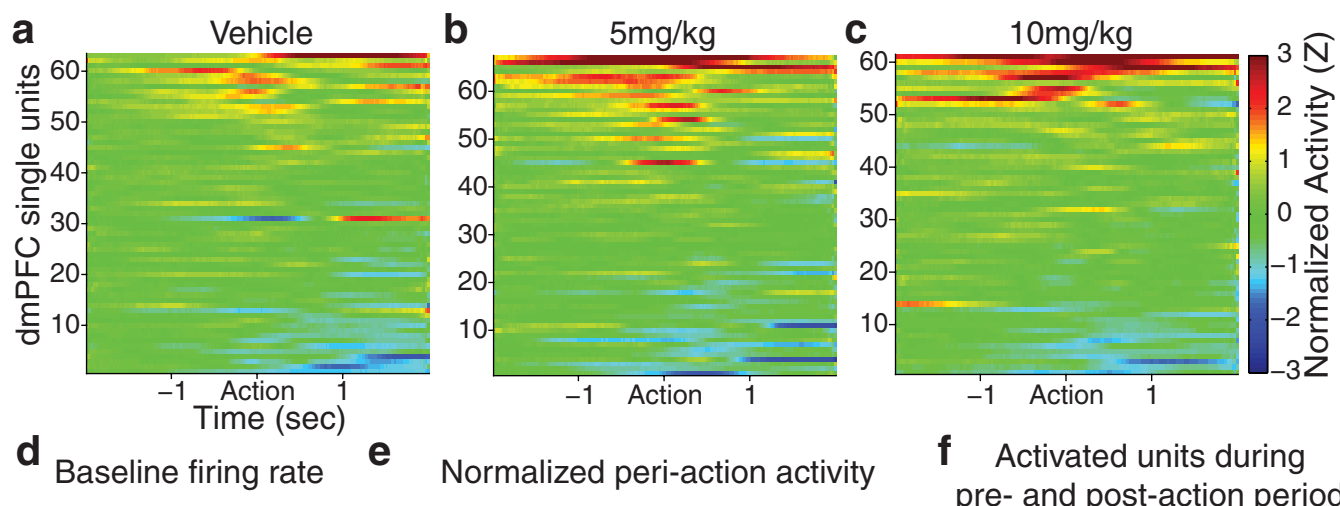

f Activated units during pre- and post-action period
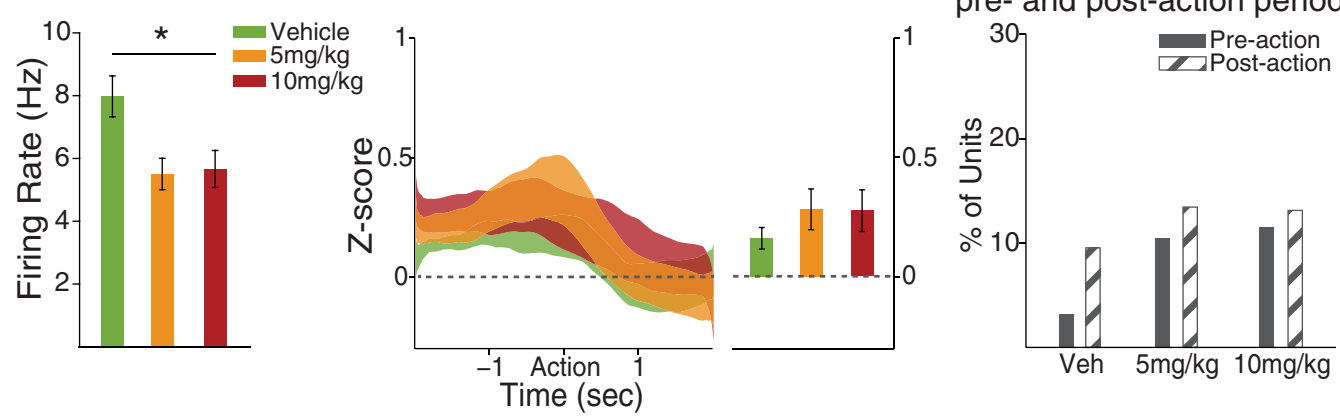

Figure 3. dmPFC periaction neuronal activity during the set-shifting task. $\boldsymbol{a}-\boldsymbol{c}$, The baseline-normalized periaction activity of vehicle- or FG7142-treated units with the action occurring at time $=0$, aligned to the time of the nose poke detected by the beam break at the cue port. dmPFC units tended to start modulating their activity preceding the action. The number of units $(n)$ and rats $(N)$ : vehicle, $n=63, N=8 ; 5 \mathrm{mg} / \mathrm{kg}, n=67, N=8 ; 10 \mathrm{mg} / \mathrm{kg}, n=61, N=7$. , The mean baseline firing rates of FG7142-injected units, measured during intertrial intervals, were significantly lower than vehicle units, consistent with the effect observed in home cage recording. Error bars indicate SE. *Statistically significant difference compared with vehicle. $\boldsymbol{e}$, Left, The normalized population activity during the periaction period is displayed as mean \pm SE (shaded area). Right, The mean population activity within the 2 s preaction period. $f$, The percentages of units classified as "Activated" in preaction and postaction periods were not significantly different across dose groups. Few units were classified as "Inhibited."

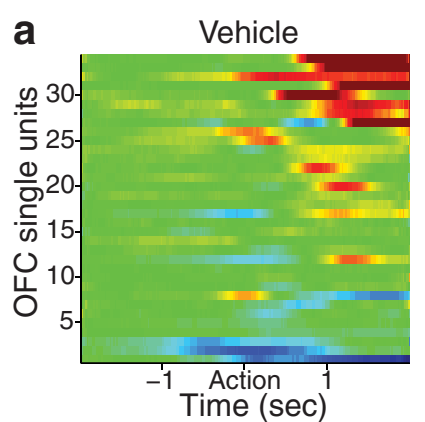

d

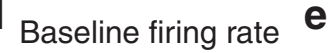

b

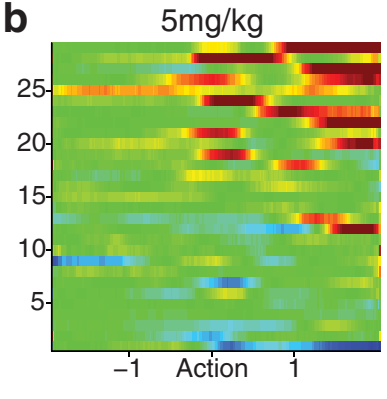

Normalized peri-action activity

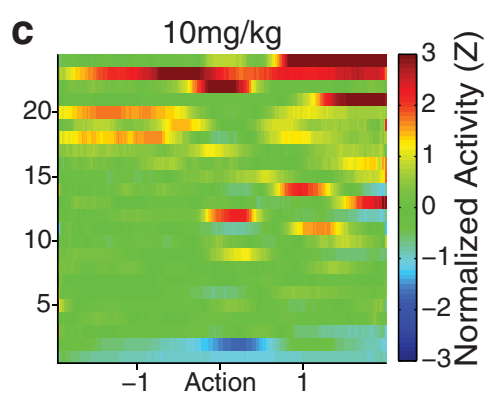

f Activated units during pre- and post-action period
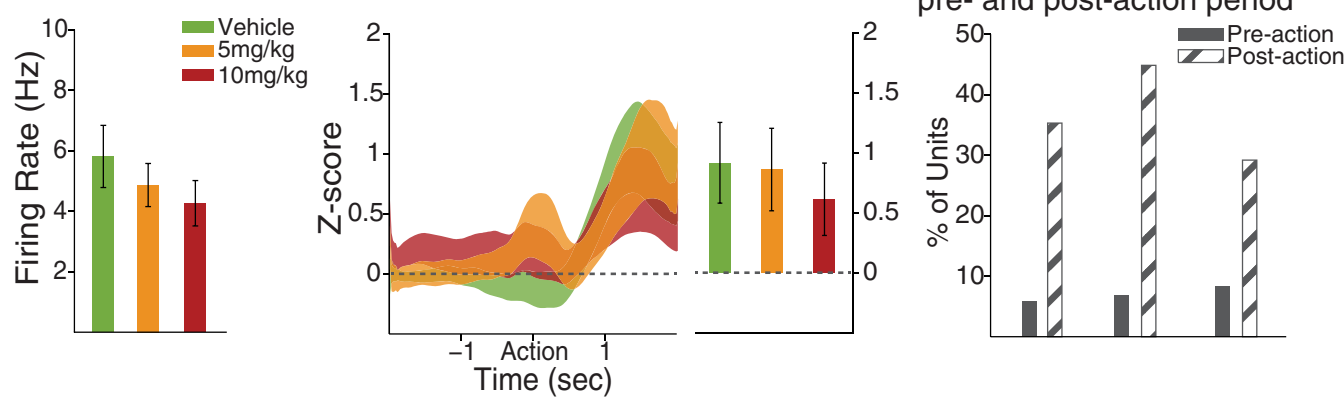

Figure 4. OFC periaction neuronal activity during the set-shifting task. $\boldsymbol{a}-\boldsymbol{c}$, The baseline-normalized periaction activity of vehicle- or FG7142-treated units with the action occurring at time $=0.0 F C$ units tended to modulate their activity during the postaction period. The number of units $(n)$ and rats ( $N)$ : vehicle, $n=34, N=5 ; 5 \mathrm{mg} / \mathrm{kg}, n=29, N=5 ; 10 \mathrm{mg} / \mathrm{kg}$, $n=24, N=4$. $d$, The mean baseline firing rate of FG7142-exposed units was numerically lower than vehicle units, consistent with the effect observed during home cage recording. Error bars indicate SE. $\boldsymbol{e}$, Left, The normalized population activity during the postaction period is displayed as mean \pm SE (shaded area). Right, The mean population activity within the $2 \mathrm{~s}$ postaction period. $\boldsymbol{f}$, The percentages of units classified as "Activated" in preaction and postaction periods did not significantly differ across dose groups. Few units were classified as "Inhibited." 

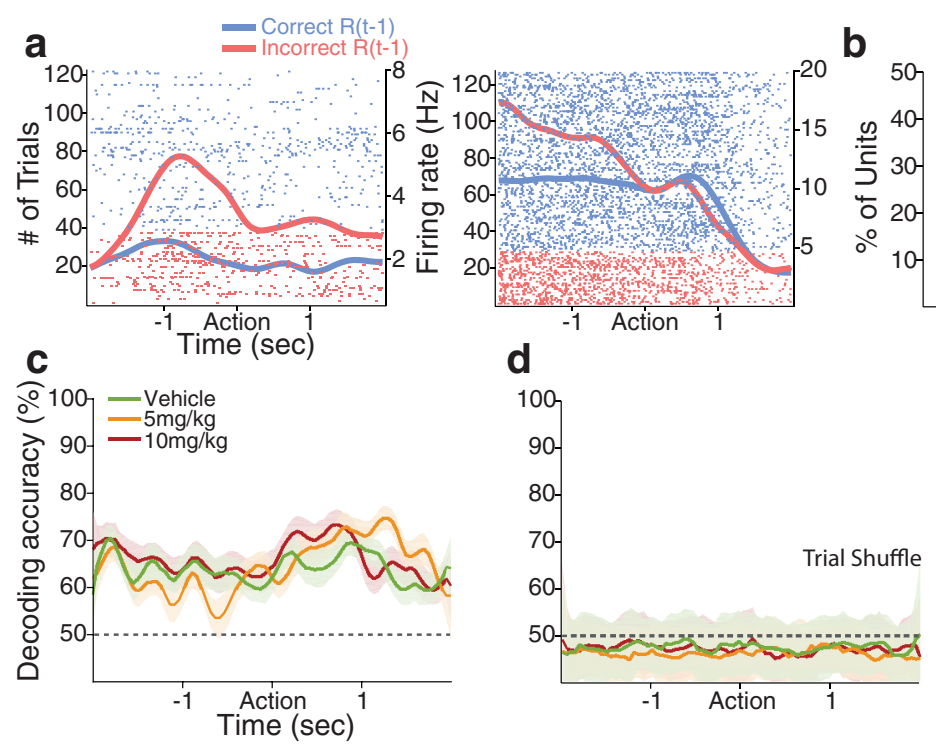

Figure 5. $d m P F C$ encoding of the previous response outcome: $R(t-1)$. $\boldsymbol{a}$, Spike raster plots of two example dmPFC units encoding the previous response outcome during the preaction period. Each row represents each trial. Each tick mark indicates a spike. Horizontal axis represents time before and after the action occurring at time $=0$. Left vertical axis represents the number of trials. Right vertical axis represents the firing rate. The spike density functions for previously correct and incorrect trials estimated with a Gaussian kernel ( $\sigma=100 \mathrm{~ms}$ ) are superimposed in each raster plot. $\boldsymbol{b}$, Proportions of vehicle and 5 and $10 \mathrm{mg} / \mathrm{kg}$ exposed units encoding the previous response outcome were not significantly different ( $n=13, n=7$, and $n=7$, respectively). c, Representation of the previous response outcome in the dmPFC population, measured by the decoding accuracy of a linear classifier. Each color-coded line indicates the decoding accuracy for the previous response outcome in each dose group (vehicle, 63 units; 5 mg/kg, 67 units; 10 mg/kg, 61 units), displayed as mean \pm SD (shaded area) across 50 resamplings. Black dotted line indicates the level of decoding expected by chance. $\boldsymbol{d}$, Shuffling the trial ID quenched the decoding accuracy for the previous response outcome to approximately the chance level.
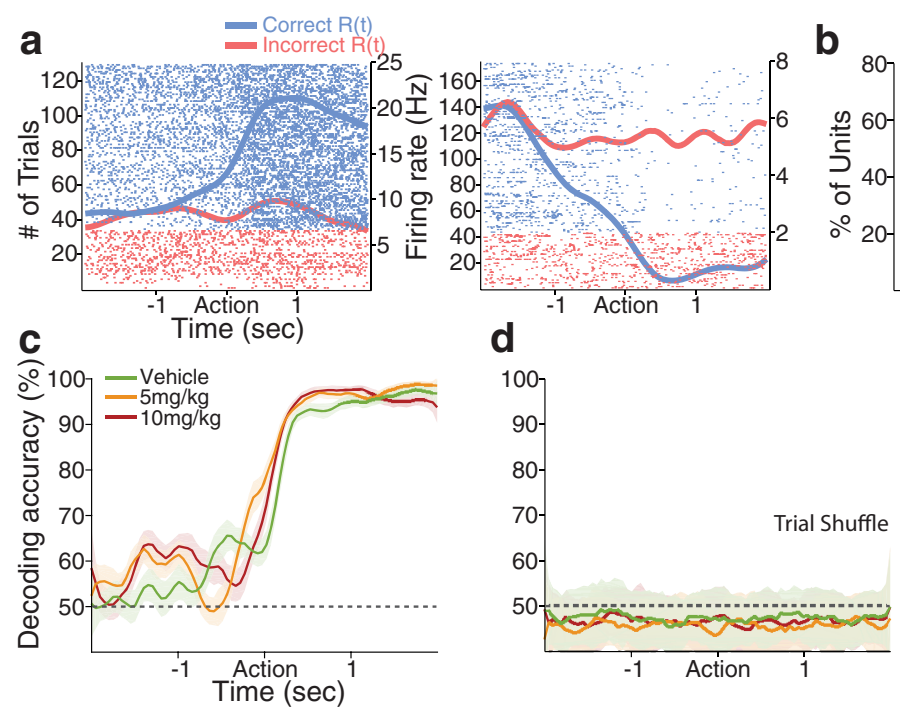

Figure 6. $d m P F C$ encoding of the current response outcome: $R(t)$. $\boldsymbol{a}$, Spike raster plots of two example dmPFC units that encoded the current response outcome during the postaction period. Format same as spike raster plots in Figure $5 a$. $\boldsymbol{b}$, Proportions of vehicle and 5 and $10 \mathrm{mg} / \mathrm{kg}$ exposed units encoding the current response outcome were similar $(n=37, n=36$, and $n=27$, respectively). $c$, The decoding accuracy for the current response outcome was highly accurate during the postaction period in all dose groups. Format same as Figure $5 c$. $\boldsymbol{d}$, Trial-shuffling extinguished the decoding accuracy for the current response outcome to approximately the chance level.

response outcomes, poke direction, and RT, using a multiple linear regression model (see Materials and Methods). We first examined the neuronal encoding of the response outcome of previous and current trials, which are the two critical features for the outcome-based guidance of behavior during the task. With all
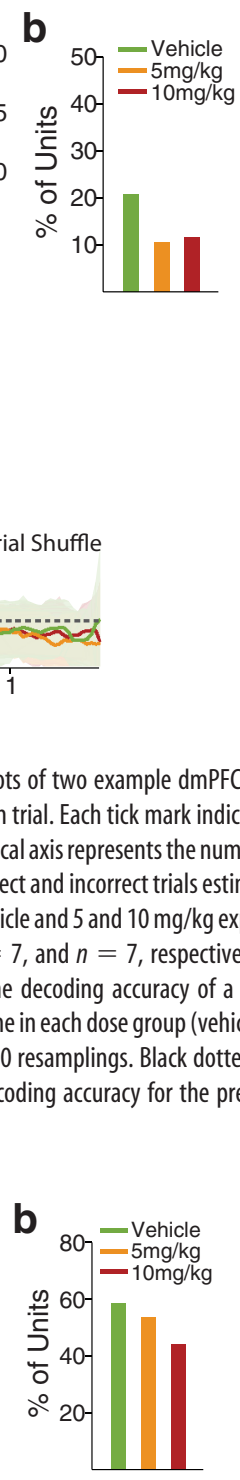

predictive variables accounting for variability in neuronal activity, some dmPFC and OFC units encoded the response outcome of the previous and/or the current trial especially during the preaction and postaction period, respectively, consistent with the literature (Sul et al., 2010; Strait et al., 2014) (Figs. 5, 6). Encoding of the previous response outcome was neither region-specific nor affected by FG7142 (Fig. 5a,b; Table $1 ; \chi^{2}$ test, $p$ values $>0.08)$. To test how reliably the previous response outcome could be decoded at the population level, we performed a decoding analysis with the entire dmPFC population of each dose group, using a linear classifier (see Materials and Methods). The response outcome of the previous trial could be decoded from the dmPFC population well above the chance level across the periaction period in all dose groups (Fig. $5 c, d$ ). Greater proportions of dmPFC and OFC units encoded the response outcome of the current trial, particularly in the postaction period, regardless of vehicle or FG7142 injection (Fig. 6a,b; Table $1 ; \chi^{2}$ test, $p$ values $>0.10)$. The classifier generated a highly accurate decoding of the current response outcome, especially during the postaction period, consistent with the individual neuronal encoding (Fig. $6 c, d$ ). In summary, substantial dmPFC and OFC units encoded previous and/or current response outcome, but this encoding was not significantly affected by the anxiogenic manipulation, suggesting that the trial-to-trial signaling of the response outcome were intact in anxiety.

The regression analysis also indicated that FG7142 treatment did not influence the fraction of units encoding previous and current poke direction in $\mathrm{dmPFC}$ (previous direction: vehicle, 17\%; $5 \mathrm{mg} /$ $\mathrm{kg}, 12 \%$; $10 \mathrm{mg} / \mathrm{kg}, 11 \%$; current direction: vehicle, $25 \% ; 5 \mathrm{mg} / \mathrm{kg}, 31 \% ; 10$ $\mathrm{mg} / \mathrm{kg}, 20 \%$ ) and OFC (previous direction: vehicle, $6 \% ; 5 \mathrm{mg} / \mathrm{kg}, 21 \% ; 10 \mathrm{mg} /$ $\mathrm{kg}, 13 \%$; current direction: vehicle, $15 \% ; 5 \mathrm{mg} / \mathrm{kg}, 31 \%$; $10 \mathrm{mg} / \mathrm{kg}, 29 \%$ ). Similar lack of effect was observed in units that encoded the RT for the action in $\mathrm{dmPFC}$ (vehicle, 17\%; $5 \mathrm{mg} / \mathrm{kg}, 12 \%$; $10 \mathrm{mg} / \mathrm{kg}, 11 \%$ ) and OFC (vehicle, 6\%; 5 $\mathrm{mg} / \mathrm{kg}, 21 \% ; 10 \mathrm{mg} / \mathrm{kg}, 13 \%$ ).

We next analyzed the neural representation of the task rule. For this, we focused on the encoding during the preaction period because it is the temporal window that immediately precedes the action, and thus encoding within this window may guide the action. A substantial fraction of vehicle-treated dmPFC units, as exemplified in Figure 7, encoded the rule in the preaction period (Fig. $8 a$ ). The anxiogenic treat- 
Table 1. The number and percentage of OFC single units encoding each task variable, according to the multiple linear regression analyses ${ }^{a}$

\begin{tabular}{lcrr}
\hline & Vehicle & $5 \mathrm{mg} / \mathrm{kg}$ & $10 \mathrm{mg} / \mathrm{kg}$ \\
\hline $\mathrm{R}(\mathrm{t}-1)$, previous response outcome & $11(32 \%)$ & $7(24 \%)$ & $3(13 \%)$ \\
$\mathrm{R}(\mathrm{t})$, current response outcome & $22(65 \%)$ & $19(66 \%)$ & $14(58 \%)$ \\
$\mathrm{D}(\mathrm{t}-1)$, previous poke direction & $2(6 \%)$ & $6(21 \%)$ & $3(13 \%)$ \\
$\mathrm{D}(\mathrm{t})$, current poke direction & $5(15 \%)$ & $9(31 \%)$ & $7(29 \%)$ \\
$\mathrm{RT}(\mathrm{t})$, reaction time & $2(6 \%)$ & $6(21 \%)$ & $3(13 \%)$ \\
$\mathrm{TR}(\mathrm{t})$, task rule & $10(29 \%)$ & $5(17 \%)$ & $6(25 \%)$ \\
$\mathrm{TR}(\mathrm{SiCF})$, task rule (side CF vs light) & $7(20 \%)$ & $4(14 \%)$ & $4(17 \%)$ \\
TR(LiCF), task rule (light CF vs side) & $4(12 \%)$ & $4(14 \%)$ & $6(25 \%)$ \\
\hline
\end{tabular}

${ }^{a}$ Equivalent proportions of OFC units encoded each task variable, as none of the examined variables differs significantly across dose groups.

ment significantly reduced the proportion of rule-encoding units (Fig. $8 a ; \chi^{2}$ test, $\chi_{1}^{2}=5.11, p=0.02$ ). The standardized regression coefficients for the task rule covariate of all rule-encoding and nonencoding units are shown across the periaction time period in Figure $8 b$. The neural representation of the task rule may gradually evolve after shifting, as the animals initially try to figure out the valid rule by trial and error, and finally attain the rule in the later phase of the set. We tested this by comparing the degrees of neural discriminability based on the rule in the two subsets of data comprising the first half and the second half trials of each set, using a sliding ROC analysis (see Materials and Methods). We found that the vast majority of the rule-encoding dmPFC units in the vehicle (19 of 24 units, paired $t$ test, $t_{(23)}=3.35, p=0.003$ ) and the $5 \mathrm{mg} / \mathrm{kg}$ ( 15 of 21 units, paired $t$ test, $t_{(20)}=3.69, p=$ $0.001)$ groups showed enhanced selectivity in the late compared with the early phase of a set (Fig. $8 c$ ). The emerging ROC values from the first to second half of trials corresponded to low and high behavioral accuracy (Fig. $8 d$; overall percentage correct: $66 \%$ and $87 \%$ ), demonstrating the association between emerging neural representation of the rule and growing behavioral accuracy. The emerging pattern of rule selectivity was weakened after animals received the $10 \mathrm{mg} / \mathrm{kg}$ dose (Fig. $8 c ; 7$ of 12 units, paired $t$ test, $t_{(11)}=1.34, p=0.21$ ), even when the behavioral choice accuracy appeared high in the second half (Fig. $8 d$ ).

Reduced individual neuronal rule representation should be associated with diminished encoding of the rule at the population level. We corroborated this using the linear classifier. The classifier decoded the task rule corresponding to current trials with high accuracy from the vehicle population, but with far lower accuracy from the $10 \mathrm{mg} / \mathrm{kg}$ population, indicating that the anxiogenic manipulation was associated with reduced rule representation by the dmPFC population (Fig. 9).

We next investigated the impact of the anxiogenic treatment on neural representation of the task rule in CF trials. We identified the CF trials in either side- or light rule sets (Fig. 2a) and then examined the encoding of CF trials of one rule, relative to the trials of the other rule, using a multiple linear regression model (see Materials and Methods). Examples of individual dmPFC units that encoded side CF trials relative to light rule trials are shown in Figure $10 a$. Figure $10 b$ illustrates that the proportion of side CF trial encoding dmPFC units was significantly reduced by $10 \mathrm{mg} / \mathrm{kg}$ FG7142 compared with vehicle $\left(\chi^{2}\right.$ test, $\chi_{1}^{2}=5.83, p=$ 0.016 ). This is consistent with the behavior data (Fig. $2 e$ ) showing increased error propensity in side CF trials at this dose. Fewer rule-encoding units were found in CF trials of the light rule, regardless of the dose (Fig. $10 b ; \chi^{2}$ test, $p$ values $>0.39$ ), which is consistent with the comparable performance across dose groups observed in these trials (Fig. 2e). The difference between the fractions of rule-encoding units in side CF and light CF trials may reflect differential degrees of rule representation between these trials (i.e., more robust rule representation may be observed in side CF than light CF trials). To test this, we applied an ROC analysis to the rule-encoding dmPFC units identified earlier without subdivision of CF and NCF trials (Fig. $8 a$ ) and quantified their discriminability of the rule for side CF and light CF trials (see Materials and Methods). We found that greater numbers of rule-encoding dmPFC units in the vehicle ( 15 of 24 units, paired $t$ test, $\left.t_{(23)}=2.36, p=0.027\right)$ and the $5 \mathrm{mg} / \mathrm{kg}$ ( 14 of 21 units, paired $t$ test, $\left.t_{(20)}=2.28, p=0.034\right)$ groups showed enhanced discriminability in the side CF than light CF trials (Fig. 10c). This difference was dampened in $10 \mathrm{mg} / \mathrm{kg}$ treated units (6 of 12 , paired $t$ test, $t_{(11)}=0.91, p=0.38$ ) (Fig. 10c). Thus, the dmPFC neural representation of the task rule in CF trials was more pronounced under the side rule, where the conflicting light stimulus was presented explicitly and continuously throughout a set. The reduction of this representation by the anxiogenic treatment may underlie its effect on increased error propensity and performance bias.

Weaker task-rule representation was observed in the OFC, as fewer proportions of rule-encoding OFC units were found, without a significant difference across dose groups (Table $1 ; \chi^{2}$ test, $p$ values $>0.25$ ). Likewise, the $\mathrm{OFC}$ rule representation in CF trials was not evident and was not affected by anxiety (Table $1 ; \chi^{2}$ test, $p$ values $>0.18$ ). These suggest that, unlike dmPFC neurons, OFC neurons do not encode anxiety-induced changes in rule-based task performance.

\section{FG7142 effect on anxiety-like behavior and locomotion measured on the elevated plus maze}

Consistent with previous reports (Pellow and File, 1986; Cole et al., 1995; Atack et al., 2005; Evans and Lowry, 2007), FG7142 induced an anxiety-like state when measured using the EPM (Fig. $11 a, b)$. Rats placed on the EPM after injection of FG7142 showed significantly fewer entries (Fig. $11 c$; independent $t$ test, $t_{(12)}=$ 3.03, $p=0.01$ ) and reduced time (Fig. $11 d$; independent $t$ test, $t_{(12)}=3.01, p=0.02$ ) spent in open arms, compared with vehicle-injected rats. The total distance traveled on the maze did not differ significantly between vehicle and FG7142-injected groups (Fig. $11 e$; independent $t$ test, $t_{(12)}=1.93, p=0.08$ ); thus, the anxiety-like behavior was not attributed to a deficit in locomotion.

\section{Discussion}

Anxiety has been studied extensively as a stand-alone construct in laboratory animals (e.g., Adhikari et al., 2010, 2011; Milad and Quirk, 2012; Calhoon and Tye, 2015). The results have contributed to our understanding of the brain circuits that are altered in anxious and fearful animals. Detrimental impacts of human anxiety, however, extend well beyond a general aversive "fearful" state and involve disruption of ongoing goal-directed behaviors that are necessary for day-to-day functioning. A critical example is disruption of PFC-mediated cognitive functions, such as flexible shifting to new behavioral strategies or overcoming distracting stimuli (Bishop, 2007; Eysenck et al., 2007). Here we sought to fill a fundamental void in the literature by addressing how a background state of anxiety influences encoding of flexible decision making by PFC neurons. We used a clinically relevant experimental model of anxiety while recording from $\mathrm{dmPFC}$ and OFC neurons of rats at wakeful rest or while they were engaged in an extradimensional set-shifting task. We find that anxiety engrosses a substantial number of spontaneously active PFC neurons and, more importantly, leads to diminished representation 

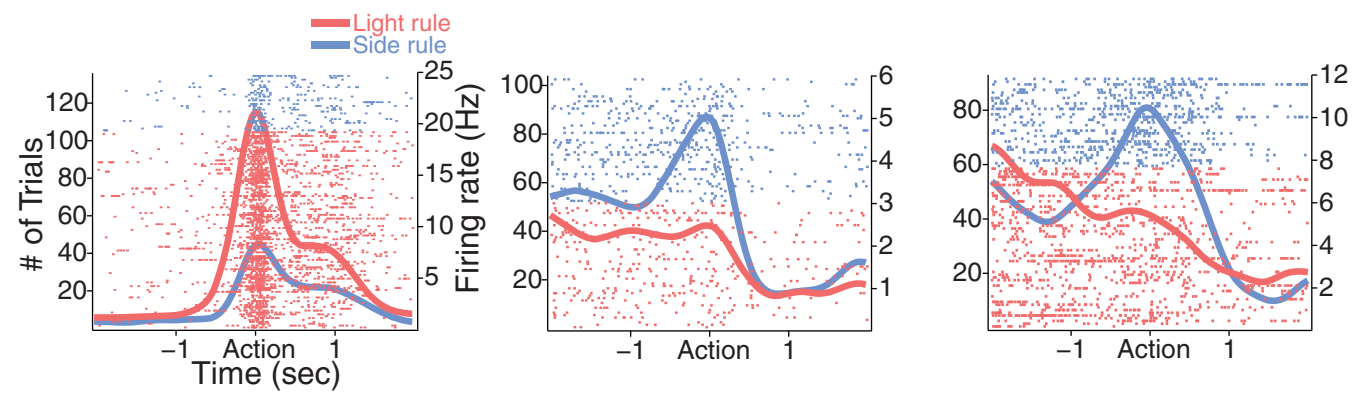

Figure 7. Example dmPFC units encoding the task rule during the preaction and postaction periods. Format same as spike raster plots in Figures 5 and 6.
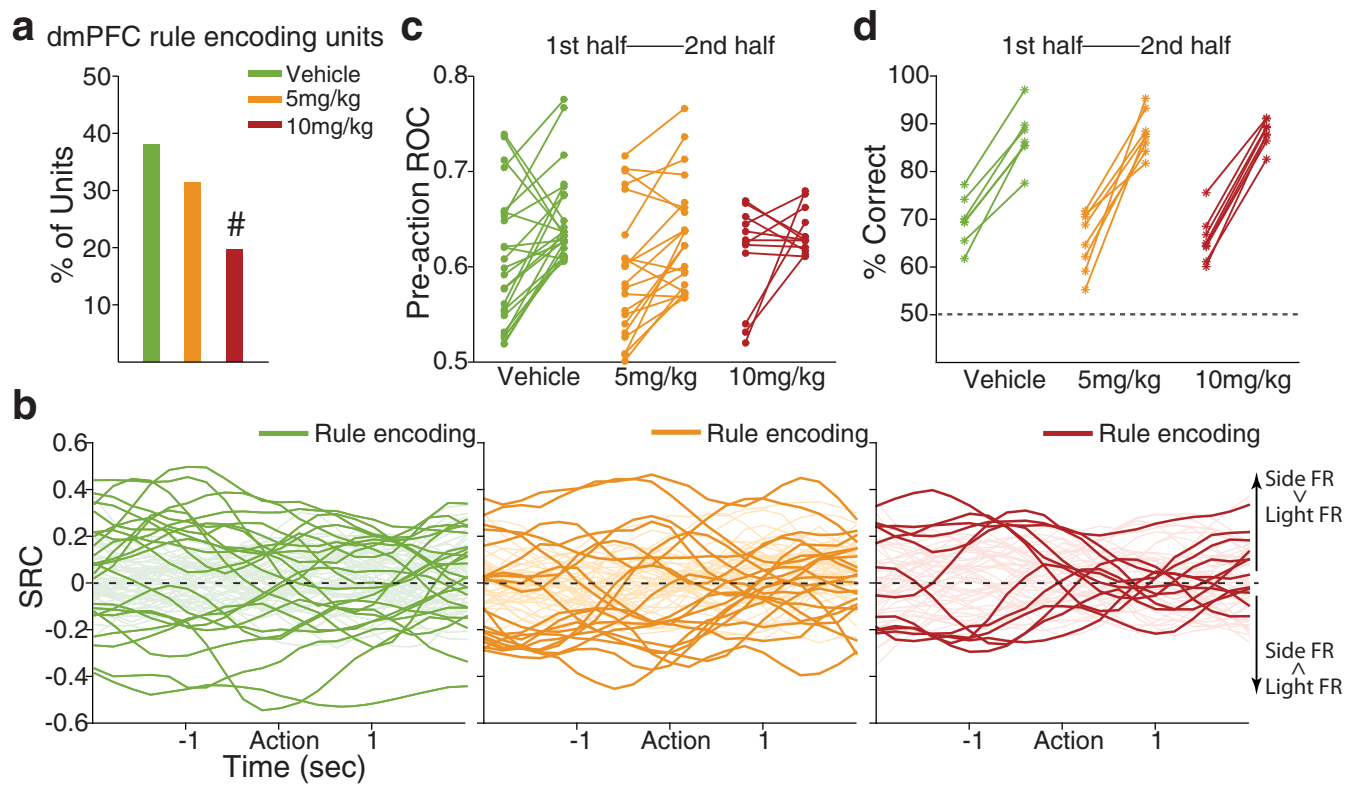

Figure 8. $\mathrm{dm} P F C$ neuronal representation of the task rule. $\boldsymbol{a}$, Bar plot represents the proportion of dmPFC units encoding the rule during the preaction period (vehicle, $24 \mathrm{units} ; 5 \mathrm{mg} / \mathrm{kg}, 21 \mathrm{units}$; $10 \mathrm{mg} / \mathrm{kg}, 12$ units). "Significantly different proportion of encoding units compared with that of the vehicle units. $\boldsymbol{b}$, Standardized regression coefficients (SRC) for the task rule covariate of the multiple linear regression model are plotted. Dark-colored lines represent SRCs for rule-encoding dmPFC units in each dose group. Light-colored lines represent SRCS for the nonencoding units. Positive-valued SRCs indicate greater firing rates (FR) in the side rule compared with the light rule, whereas negative-valued SRCs indicate greater firing rates in the light rule. $c$, The degrees of neural discriminability based on the rule were examined in the two subsets of data comprising the first half and the second half trials of each set, using an ROC analysis. For each dose group, the left and right filled circles represent the preaction ROC values of the first and the second half trials, respectively, of the rule-encoding units. An emerging trend of rule selectivity was observed from first to second half trials, which was blunted in the $10 \mathrm{mg} / \mathrm{kg}$ treated units. $\boldsymbol{d}$, The percentage of correct choices for the first half (left asterisks) and the second half (right asterisks) trials of each animal is indicated for a comparison with the ROC data.

of conflict-related action by dmPFC neurons in correlation with behavioral impairment.

\section{The challenge of modeling sustained anxiety in behaving animals}

Anxiety is a construct in Research Domain Criteria of National Institute of Mental Health's Strategic Plan and a debilitating symptom of most psychiatric disorders. Anxiety generally is not a rapid neuronal "event" but a "state" that may be sustained for many minutes to hours. In a real-life situation, the impact of anxiety extends beyond its general aversive state and impairs ongoing behaviors that use cognitive and affective processing. The neurodynamic nature of this impairment has been difficult to address, in part, because previous electrophysiological studies focused on fear conditioning and avoidance paradigms as a potential measure of anxiety. Although these studies have revealed a role for PFC in regulating freezing and avoidance behaviors (Milad and Quirk, 2002; Burgos-Robles et al., 2009), they cannot reveal how the PFC neural correlates of cognitive and motivated behavioral events are modulated by anxiety.
To study anxiety-related PFC neural processing during cognitive and motivated behaviors, it would be ideal to produce a sustained state of anxiety in animals that does not prevent their task performance. We used a pharmacological model of sustained anxiety that has excellent cross-species validity. Inverse agonists of allosteric benzodiazepine binding sites in $\mathrm{GABA}_{\mathrm{A}}$ receptors produce an anxiogenic state (Evans and Lowry, 2007). This is an "old" approach, with one of the initial studies (Ninan et al., 1982) reporting a behavioral syndrome in rhesus monkeys that mimicked physiological and affective features of human anxiety. Although these drugs produce freezing or may have proconvulsive properties at very high doses, their symptomatic impact at moderate doses is relatively specific in the context of anxiety, in that behavioral and perceptual effects unrelated to anxiety (such as hallucination) are not reported. A well-characterized drug in this class is FG7142, which has been shown to produce PFCmediated cognitive deficits (Murphy et al., 1996a), as well as anxiety-related cardiovascular, and neurochemical effects in humans and laboratory animals (Evans and Lowry, 2007). This ap- 
proach provided a practical tool for studying the impact of sustained anxiety on cognitive task performance.

\section{Effects of anxiety on spontaneous PFC activity}

Anxiety induced by FG7142 suppressed dmPFC and OFC population activity. This effect contrasts the increase in PFC firing rate shown previously in traditional rodent models of anxiety (Adhikari et al., 2011). Our findings, however, are consistent with human imaging studies that have reported reduced activation of PFC in patients with anxiety disorders (Shin et al., 2001; Phelps et al., 2004). These data further suggest that the "hypofrontality" commonly associated with a general state of anxiety is caused by suppression of the spontaneously active PFC neurons.

Anxiogenic compounds, including FG7142, decrease the chloride flux via $\mathrm{GABA}_{\mathrm{A}}$ receptors, which should produce a direct excitatory effect on firing rate of single neurons. The observed inhibitory influence, therefore, suggests the involvement of networks of GABA interneurons and multiple inhibitory processes mediated by them (White et al., 2000). Alternatively, similar to stress, indirect mechanisms, such as activation of noradrenergic or dopaminergic projections to the PFC, may be involved (Reinhard et al., 1982; Goldstein et al., 1996; Arnsten, 2000; Gamo et al., 2015). Dopamine recently has been implicated in mediating anxiety-like behaviors (Lammel et al., 2012). Selective activation of dopamine release in mPFC by the fiber photometry had anxiogenic effects in mice (Gunaydin et al., 2014). A hyper-reactive mesoprefrontal circuit was associated with clinical anxiety in humans (Cha et al., 2014). Consistent with PFC activation of dopamine release being anxiogenic, FG7142 produces a sustained increase in dopamine release selectively in the PFC (Bradberry et al., 1991; Murphy et al., 1996a). Importantly, the time course of increase in dopamine release is similar to the duration of PFC neuronal inhibition we observed (Bradberry et al., 1991). Postsynaptic effects of dopamine on PFC neurons are primarily inhibitory (Sesack and Bunney, 1989; Seamans et al., 2001; Gorelova et al., 2002); thus, the anxiety-induced reduction in PFC neuronal activity may be mediated, in part, by selective activation of dopamine release in PFC. Of note, high levels of dopamine D1 or noradrenergic $\alpha$-1 receptor stimulation, similar to the impact of FG7142, reduce PFC neuronal firing in monkeys (Arnsten, 2009).

\section{Modality-specific deficits in set-shifting task performance}

The dose of the anxiogenic compound used here did not prevent animals from successfully completing trials in the set-shifting task. This allowed us to unveil selective and clinically relevant anxiety-induced deficits in rule-shifting behavior. A critical aspect of our task was that it included multiple extradimensional shifts within each session. Animals had been well trained with the discrimination rules as well as shifting between them before the test session; thus, the task was sensitive to measure the flexible switching between rules based on the action-outcome contin- gency. FG7142-injected rats readily shifted from the side to the light rule, as evidenced by fewer errors and trials to criterion in the light rule. However, when shifting to the side rule, increased errors were observed during what we coined "conflict trials" (i.e., trials where light was presented in the incorrect side). This selective deficit suggests impaired capacity to disengage from the previously relevant sensory dimension, especially when the outmoded cue was visible. This deficit is consistent with increased perseverative errors after acute stress in rodents (Butts et al., 2013) and monkeys (Murphy et al., 1996a, b), and perseverative behavioral patterns in patients with anxiety-related disorders (Purcell et al., 1998; Eysenck et al., 2007).

Our observation further suggests that the detrimental impact of anxiety on rule shifting is modality specific and especially vulnerable when a shift is required in the presence of previously relevant sensory stimuli. From a broader standpoint, these behavioral findings indicate that anxiety may bias decision making to a sensory-based process that is less flexible and more prone to visual and other sensory distractors. These findings, therefore, support the notion that, under anxiety, behavioral selection is skewed by salient environmental stimuli at the expense of flexible top-down guided choices.

\section{Neuronal encoding of deficits in behavioral rule shifting in anxiety}

The baseline firing rates of $\mathrm{dmPFC}$ and OFC neurons were similarly inhibited by the anxiogenic treatment during home cage recording and task performance. During task performance, varying degrees of neuronal encoding of the response outcome, choice direction, and RT were observed in both regions, and signaling of these variables involving a trial-to-trial processing 


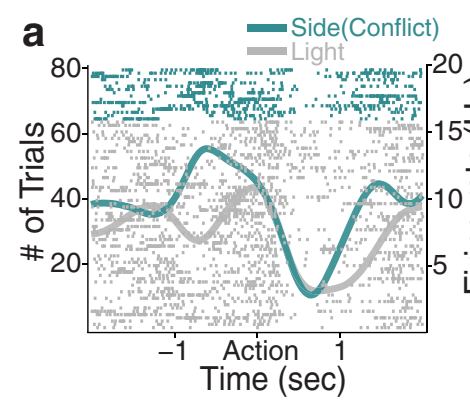

b dmPFC rule encoding units

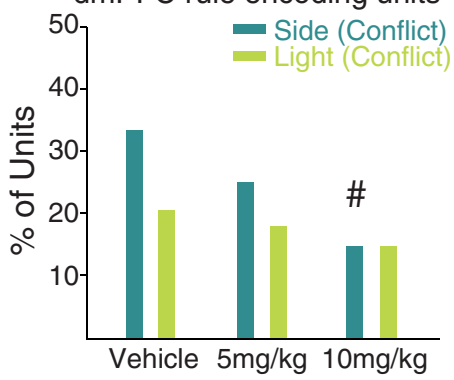

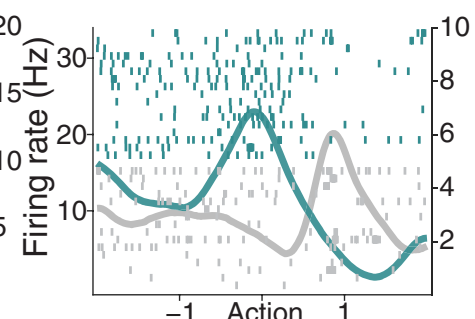

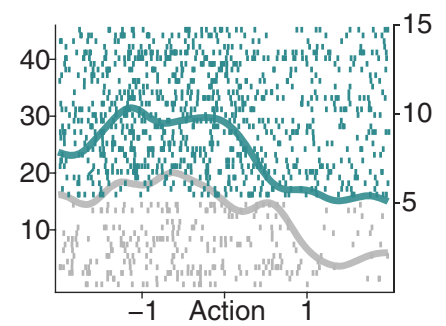

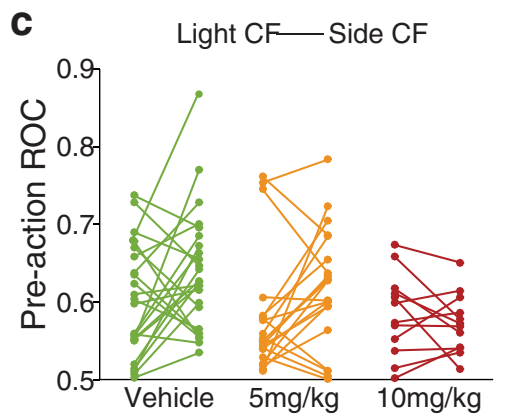

Figure 10. dmPFC neuronal encoding of the task rule, examined specifically in conflict trials. $\boldsymbol{a}$, The spike raster plots of example dmPFC units that discriminatively represented side (conflict) and light trials during the preaction period. Format same as spike raster plots above. $\boldsymbol{b}$, Bar plot represents the proportion of dmPFC rule-encoding units in side CF (vehicle, 21 units; 5 mg/kg, 18 units; $10 \mathrm{mg} / \mathrm{kg}, 9$ units) and light (F (vehicle, 13 units; $5 \mathrm{mg} / \mathrm{kg}, 12$ units; $10 \mathrm{mg} / \mathrm{kg}, 9$ units) trials during the preaction period. The proportion of rule-encoding units in side (F trials decreased in a dose-dependent manner. "Significantly different proportion of encoding units compared with that of the vehicle units. $c$, The neural discriminability of light CF or side CF trials, relative to the trials of the other rule, was quantified using an ROC analysis. Each line segment represents an individual rule-encoding unit's ROC value for the light CF trials (left filled circle) and the side CF trials (right filled circle).
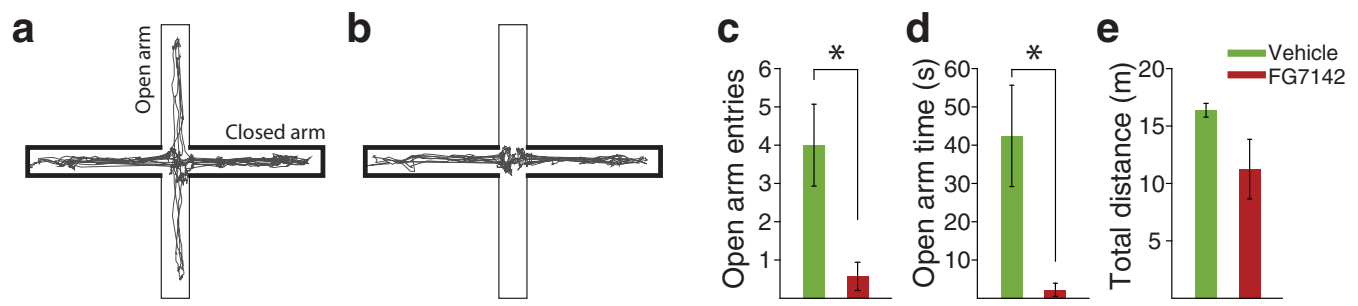

Figure 11. Anxiogenic effect of FG7142 measured on the elevated plus maze. $\boldsymbol{a}, \boldsymbol{b}$, A representative trajectory of a vehicle (a) or $10 \mathrm{mg} / \mathrm{kg}$ FG7142 ( $\boldsymbol{b})$ injected rat. $\boldsymbol{c}$, The number of open arm entries. $\boldsymbol{d}$, Time spent in the open arms. $\boldsymbol{e}$, Total distance traveled on the maze. Number $(N)$ of rats: vehicle, $N=7 ; 10 \mathrm{mg} / \mathrm{kg}, N=7$. Error bars indicate SE. *Statistically significant difference compared with vehicle.

was not significantly affected by anxiety. In contrast, the dmPFC neural representation of task rules was selectively diminished. Encoding the task rule is a higher-order process that involves representation of relationships among the task-relevant cues, actions, and outcomes. Thus, our finding suggests that the higherorder processing, subserved by dmPFC, may be particularly susceptible to anxiety.

Further analyses of the neural representation of the task rule revealed dynamic aspects of the $\mathrm{dmPFC}$ rule encoding and its vulnerability to anxiety. First, the rule representation gradually evolved after the set-shifting. This growing representation is unlikely to be an epiphenomenon of the enhanced correct choices or increased "confidence" in choice because equivalent enhancement in behavioral accuracy was observed in both rules. Thus, the growing rule representation may contribute to the gradual improvement in choice accuracy. This emerging pattern in the rule representation collapsed in anxiety, suggesting that this component of rule representation is vulnerable to anxiety. Second, we observed that dmPFC rule representation was different in side versus light CF trials. This can be attributed to the fact that conflict arises more explicitly in the side rule due to the continuous presence of the salient light cue. The rule representation in the side CF trials was disrupted in anxiety in correlation with increased performance errors. Collectively, these data indicate that the anxiety-related alterations in task performance are associated with deteriorated dmPFC representation of the task rule.

Our analyses revealed that fewer proportions of OFC, compared with dmPFC, neurons signaled rule-relevant information. The majority of OFC neurons modulated their activity in the postaction period when the response outcome was presented, suggesting specialized roles of $\mathrm{dmPFC}$ and $\mathrm{OFC}$ in encoding distinct information during a rewarded and complex cognitive task (i.e., task rule vs response outcome), consistent with previous literature (Dias et al., 1997; McAlonan and Brown, 2003; Bissonette et al., 2008). It should be underscored that these findings do not discount a role for OFC in mediating other adverse effects of anxiety.

In conclusion, the model of anxiety used here has been validated in humans and monkeys. Although this model is different from conventional rodent models of anxiety, the fact that the type of cognitive deficits and the hypofrontality associated with this model parallel observations in the human anxiety literature, enhances the clinical relevance of our electrophysiology and com- 
putational results. These results provide mechanistic insight for how anxiety diminishes rule-based guidance of behavior, leading to performance bias, and increased error propensity in decision making under conflict. They also single out encoding of actions by PFC neurons as particularly vulnerable to anxiety.

\section{References}

Adhikari A (2014) Distributed circuits underlying anxiety. Front Behav Neurosci 8:112. CrossRef Medline

Adhikari A, Topiwala MA, Gordon JA (2010) Synchronized activity between the ventral hippocampus and the medial prefrontal cortex during anxiety. Neuron 65:257-269. CrossRef Medline

Adhikari A, Topiwala MA, Gordon JA (2011) Single units in the medial prefrontal cortex with anxiety-related firing patterns are preferentially influenced by ventral hippocampal activity. Neuron 71:898-910. CrossRef Medline

Arnsten AF (2000) Stress impairs prefrontal cortical function in rats and monkeys: role of dopamine D1 and norepinephrine alpha-1 receptor mechanisms. Prog Brain Res 126:183-192. CrossRef Medline

Arnsten AF (2009) Stress signalling pathways that impair prefrontal cortex structure and function. Nat Rev Neurosci 10:410-422. CrossRef Medline

Atack JR, Hutson PH, Collinson N, Marshall G, Bentley G, Moyes C, Cook SM, Collins I, Wafford K, McKernan RM, Dawson GR (2005) Anxiogenic properties of an inverse agonist selective for alpha3 subunitcontaining GABA A receptors. Br J Pharmacol 144:357-366. CrossRef Medline

Bishop SJ (2007) Neurocognitive mechanisms of anxiety: an integrative account. Trends Cogn Sci 11:307-316. CrossRef Medline

Bissonette GB, Martins GJ, Franz TM, Harper ES, Schoenbaum G, Powell EM (2008) Double dissociation of the effects of medial and orbital prefrontal cortical lesions on attentional and affective shifts in mice. J Neurosci 28:11124-11130. CrossRef Medline

Bradberry CW, Lory JD, Roth RH (1991) The anxiogenic beta-carboline FG 7142 selectively increases dopamine release in rat prefrontal cortex as measured by microdialysis. J Neurochem 56:748-752. CrossRef Medline

Burgos-Robles A, Vidal-Gonzalez I, Quirk GJ (2009) Sustained conditioned responses in prelimbic prefrontal neurons are correlated with fear expression and extinction failure. J Neurosci 29:8474-8482. CrossRef Medline

Butts KA, Floresco SB, Phillips AG (2013) Acute stress impairs set-shifting but not reversal learning. Behav Brain Res 252:222-229. CrossRef Medline

Calhoon GG, Tye KM (2015) Resolving the neural circuits of anxiety. Nat Neurosci 18:1394-1404. CrossRef Medline

Cha J, Carlson JM, Dedora DJ, Greenberg T, Proudfit GH, Mujica-Parodi LR (2014) Hyper-reactive human ventral tegmental area and aberrant mesocorticolimbic connectivity in overgeneralization of fear in generalized anxiety disorder. J Neurosci 34:5855-5860. CrossRef Medline

Cole BJ, Hillmann M, Seidelmann D, Klewer M, Jones GH (1995) Effects of benzodiazepine receptor partial inverse agonists in the elevated plus maze test of anxiety in the rat. Psychopharmacology 121:118-126. CrossRef Medline

Darrah JM, Stefani MR, Moghaddam B (2008) Interaction of N-methyl-Daspartate and group 5 metabotropic glutamate receptors on behavioral flexibility using a novel operant set-shift paradigm. Behav Pharmacol 19:225-234. CrossRef Medline

Dias R, Robbins TW, Roberts AC (1997) Dissociable forms of inhibitory control within prefrontal cortex with an analog of the Wisconsin Card Sort Test: restriction to novel situations and independence from "online" processing. J Neurosci 17:9285-9297. Medline

Dorow R (1987) FG 7142 and its anxiety-inducing effects in humans. Br J Clin Pharmacol 23:781-782. Medline

Durstewitz D, Vittoz NM, Floresco SB, Seamans JK (2010) Abrupt transitions between prefrontal neural ensemble states accompany behavioral transitions during rule learning. Neuron 66:438-448. CrossRef Medline

Evans AK, Lowry CA (2007) Pharmacology of the beta-carboline FG-7142, a partial inverse agonist at the benzodiazepine allosteric site of the GABA A receptor: neurochemical, neurophysiological, and behavioral effects. CNS Drug Rev 13:475-501. CrossRef Medline

Eysenck MW, Derakshan N, Santos R, Calvo MG (2007) Anxiety and cognitive performance: attentional control theory. Emotion 7:336-353. CrossRef Medline

Floresco SB, Block AE, Tse MT (2008) Inactivation of the medial prefrontal cortex of the rat impairs strategy set-shifting, but not reversal learning, using a novel, automated procedure. Behav Brain Res 190:85-96. CrossRef Medline

Gamo NJ, Lur G, Higley MJ, Wang M, Paspalas CD, Vijayraghavan S, Yang Y, Ramos BP, Peng K, Kata A, Boven L, Lin F, Roman L, Lee D, Arnsten AF (2015) Stress impairs prefrontal cortical function via D1 dopamine receptor interactions with hyperpolarization-activated cyclic nucleotidegated channels. Biol Psychiatry 78:860-870. CrossRef Medline

Goldstein LE, Rasmusson AM, Bunney BS, Roth RH (1996) Role of the amygdala in the coordination of behavioral, neuroendocrine, and prefrontal cortical monoamine responses to psychological stress in the rat. J Neurosci 16:4787-4798. Medline

Gorelova N, Seamans JK, Yang CR (2002) Mechanisms of dopamine activation of fast-spiking interneurons that exert inhibition in rat prefrontal cortex. J Neurophysiol 88:3150-3166. CrossRef Medline

Gunaydin LA, Grosenick L, Finkelstein JC, Kauvar IV, Fenno LE, Adhikari A, Lammel S, Mirzabekov JJ, Airan RD, Zalocusky KA, Tye KM, Anikeeva P, Malenka RC, Deisseroth K (2014) Natural neural projection dynamics underlying social behavior. Cell 157:1535-1551. CrossRef Medline

Hains AB, Arnsten AF (2008) Molecular mechanisms of stress-induced prefrontal cortical impairment: implications for mental illness. Learn Mem 15:551-564. CrossRef Medline

Hamilton JP, Chen MC, Waugh CE, Joormann J, Gotlib IH (2015) Distinctive and common neural underpinnings of major depression, social anxiety, and their comorbidity. Soc Cogn Affect Neurosci 10:552-560. CrossRef Medline

Homayoun H, Moghaddam B (2007) NMDA receptor hypofunction produces opposite effects on prefrontal cortex interneurons and pyramidal neurons. J Neurosci 27:11496-11500. CrossRef Medline

Lammel S, Lim BK, Ran C, Huang KW, Betley MJ, Tye KM, Deisseroth K, Malenka RC (2012) Input-specific control of reward and aversion in the ventral tegmental area. Nature 491:212-217. CrossRef Medline

Lee D (2013) Decision making: from neuroscience to psychiatry. Neuron 78:233-248. CrossRef Medline

Likhtik E, Stujenske JM, Topiwala MA, Harris AZ, Gordon JA (2014) Prefrontal entrainment of amygdala activity signals safety in learned fear and innate anxiety. Nat Neurosci 17:106-113. CrossRef Medline

Lüthi A, Lüscher C (2014) Pathological circuit function underlying addiction and anxiety disorders. Nat Neurosci 17:1635-1643. CrossRef Medline

McAlonan K, Brown VJ (2003) Orbital prefrontal cortex mediates reversal learning and not attentional set-shifting in the rat. Behav Brain Res 146: 97-103. CrossRef Medline

Meyers EM, Qi XL, Constantinidis C (2012) Incorporation of new information into prefrontal cortical activity after learning working memory tasks. Proc Natl Acad Sci U S A 109:4651-4656. CrossRef Medline

Mikkelsen JD, Søderman A, Kiss A, Mirza N (2005) Effects of benzodiazepines receptor agonists on the hypothalamic-pituitary-adrenocortical axis. Eur J Pharmacol 519:223-230. CrossRef Medline

Milad MR, Quirk GJ (2002) Neurons in medial prefrontal cortex signal memory for fear extinction. Nature 420:70-74. CrossRef Medline

Milad MR, Quirk GJ (2012) Fear extinction as a model for translational neuroscience: ten years of progress. Annu Rev Psychol 63:129-151. CrossRef Medline

Murphy BL, Arnsten AF, Goldman-Rakic PS, Roth RH (1996a) Increased dopamine turnover in the prefrontal cortex impairs spatial working memory performance in rats and monkeys. Proc Natl Acad Sci U S A 93:1325-1329. CrossRef Medline

Murphy BL, Arnsten AF, Jentsch JD, Roth RH (1996b) Dopamine and spatial working memory in rats and monkeys: pharmacological reversal of stress-induced impairment. J Neurosci 16:7768-7775. Medline

Ninan PT, Insel TM, Cohen RM, Cook JM, Skolnick P, Paul SM (1982) Benzodiazepine receptor-mediated experimental "anxiety" in primates. Science 218:1332-1334. CrossRef Medline

Ouimet AJ, Gawronski B, Dozois DJ (2009) Cognitive vulnerability to anxiety: a review and an integrative model. Clin Psychol Rev 29:459-470. CrossRef Medline

Owens DG, Miller P, Lawrie SM, Johnstone EC (2005) Pathogenesis of schizophrenia: a psychopathological perspective. Br J Psychiatry 186: 386-393. CrossRef Medline

Paxinos G, Watson C (1998) The rat brain in stereotaxic coordinates. San Diego: Academic 
Pehrson AL, Bondi CO, Totah NK, Moghaddam B (2013) The influence of NMDA and GABA(A) receptors and glutamic acid decarboxylase (GAD) activity on attention. Psychopharmacology 225:31-39. CrossRef Medline

Pellow S, File SE (1986) Anxiolytic and anxiogenic drug effects on exploratory activity in an elevated plus-maze: a novel test of anxiety in the rat. Pharmacol Biochem Behav 24:525-529. CrossRef Medline

Phelps EA, Delgado MR, Nearing KI, LeDoux JE (2004) Extinction learning in humans: role of the amygdala and vmPFC. Neuron 43:897-905. CrossRef Medline

Purcell R, Maruff P, Kyrios M, Pantelis C (1998) Cognitive deficits in obsessive-compulsive disorder on tests of frontal-striatal function. Biol Psychiatry 43:348-357. CrossRef Medline

Reinhard JF Jr, Bannon MJ, Roth RH (1982) Acceleration by stress of dopamine synthesis and metabolism in prefrontal cortex: antagonism by diazepam. Naunyn Schmiedebergs Arch Pharmacol 318:374-377. CrossRef Medline

Robinson OJ, Vytal K, Cornwell BR, Grillon C (2013) The impact of anxiety upon cognition: perspectives from human threat of shock studies. Front Hum Neurosci 7:203. CrossRef Medline

Ruglass LM, Lopez-Castro T, Cheref S, Papini S, Hien DA (2014) At the crossroads: the intersection of substance use disorders, anxiety disorders, and posttraumatic stress disorder. Curr Psychiatr Rep 16:505. CrossRef Medline

Schoenbaum G, Roesch MR, Stalnaker TA, Takahashi YK (2009) A new perspective on the role of the orbitofrontal cortex in adaptive behaviour. Nat Rev Neurosci 10:885-892. CrossRef Medline

Seamans JK, Gorelova N, Durstewitz D, Yang CR (2001) Bidirectional dopamine modulation of GABAergic inhibition in prefrontal cortical pyramidal neurons. J Neurosci 21:3628-3638. Medline
Sesack SR, Bunney BS (1989) Pharmacological characterization of the receptor mediating electrophysiological responses to dopamine in the rat medial prefrontal cortex: a microiontophoretic study. J Pharmacol Exp Ther 248:1323-1333. Medline

Shin LM, Whalen PJ, Pitman RK, Bush G, Macklin ML, Lasko NB, Orr SP, McInerney SC, Rauch SL (2001) An fMRI study of anterior cingulate function in posttraumatic stress disorder. Biol Psychiatry 50:932-942. CrossRef Medline

Solomon M, Ozonoff S, Carter C, Caplan R (2008) Formal thought disorder and the autism spectrum: relationship with symptoms, executive control, and anxiety. J Autism Dev Disord 38:1474-1484. CrossRef Medline

Sotres-Bayon F, Bush DE, LeDoux JE (2004) Emotional perseveration: an update on prefrontal-amygdala interactions in fear extinction. Learn Mem 11:525-535. CrossRef Medline

Stefani MR, Moghaddam B (2005) Systemic and prefrontal cortical NMDA receptor blockade differentially affect discrimination learning and setshift ability in rats. Behav Neurosci 119:420-428. CrossRef Medline

Strait CE, Blanchard TC, Hayden BY (2014) Reward value comparison via mutual inhibition in ventromedial prefrontal cortex. Neuron 82:13571366. CrossRef Medline

Sul JH, Kim H, Huh N, Lee D, Jung MW (2010) Distinct roles of rodent orbitofrontal and medial prefrontal cortex in decision making. Neuron 66:449-460. CrossRef Medline

White JA, Banks MI, Pearce RA, Kopell NJ (2000) Networks of interneurons with fast and slow gamma-aminobutyric acid type A (GABAA) kinetics provide substrate for mixed gamma-theta rhythm. Proc Natl Acad Sci U S A 97:8128-8133. CrossRef Medline 